University of Louisville

ThinkIR: The University of Louisville's Institutional Repository

Electronic Theses and Dissertations

$5-2011$

\title{
CFD modeling of entrance and exit geometries of a wind speed accelerator.
}

David Russ

University of Louisville

Follow this and additional works at: https://ir.library.louisville.edu/etd

Part of the Chemical Engineering Commons

\section{Recommended Citation}

Russ, David, "CFD modeling of entrance and exit geometries of a wind speed accelerator." (2011).

Electronic Theses and Dissertations. Paper 1241.

https://doi.org/10.18297/etd/1241

This Master's Thesis is brought to you for free and open access by ThinkIR: The University of Louisville's Institutional Repository. It has been accepted for inclusion in Electronic Theses and Dissertations by an authorized administrator of ThinkIR: The University of Louisville's Institutional Repository. This title appears here courtesy of the author, who has retained all other copyrights. For more information, please contact thinkir@louisville.edu. 


\title{
CFD MODELING OF ENTRANCE AND EXIT GEOMETRIES OF A WIND SPEED ACCELERATOR
}

By

David Russ

B.S., University of Louisville, 2010

\author{
A Thesis \\ Submitted to the Faculty of the \\ University of Louisville \\ J. B. Speed School of Engineering \\ as Partial Fulfillment of the Requirements \\ for the Professional Degree
}

MASTER OF ENGINEERING

Department of Chemical Engineering

May, 2011 



\title{
A COMPUTATIONAL DESIGN OF A SMALL SCALE WIND CONCENTRATOR DEVICE
}

Submitted by:

\author{
David Russ
}

A Thesis Approved On

\section{(Date)}

by the Following Reading and Examination Committee:

R. Eric Berson, Thesis Director

\begin{tabular}{c}
\hline Gerold Willing \\
\hline Yongsheng Lian \\
\hline William Komp
\end{tabular}




\section{ACKNOWLEDGEMENTS}

Thank you to Dr. William Komp, Michael Lucas, WEST Wind Power, Inc, and especially to Dr. Eric Berson for all of your help. 


\begin{abstract}
Current wind power technology is not economically feasible throughout most of the United States due to low average wind speeds. A design for a small-scale wind concentrator device suitable for use in areas of low wind velocity was tested using computational fluid dynamics (CFD). Using a novel approach, the device seeks to accelerate incoming air above minimum velocities required for economical power generation. The novel approach employs a funnel shaped inlet with relief vents along the circumference, so as to alleviate backpressure. Both inlet and outlet sections utilize funnel shapes with both parabolic and hyperbolic regions. All geometry and mesh models were created using ICEM 12.1. Simulations were performed using Fluent 12.1.2. Turbulence was modeled using the standard k-epsilon model. All mesh models contained roughly 500,000 unstructured computational cells. CFD simulations predict a $2.53 \mathrm{X}$ acceleration of incoming air through the throat of the device (based upon a $2 \mathrm{~m} / \mathrm{s}$ ambient wind speed). Similar performance was seen across the range of 1-12 m/s. Analysis focused on testing various designs to reduce losses due to turbulent energy and backpressure, with a focus on maximizing the throat velocity where a turbine can be located. Tested variables include funnel shape, lengths of both inlet and outlet funnels, and curvature of the inlet rim. In addition to design of the device, the effect on airflow through the relief vents by a surrounding casing was also analyzed.
\end{abstract}




\section{TABLE OF CONTENTS}

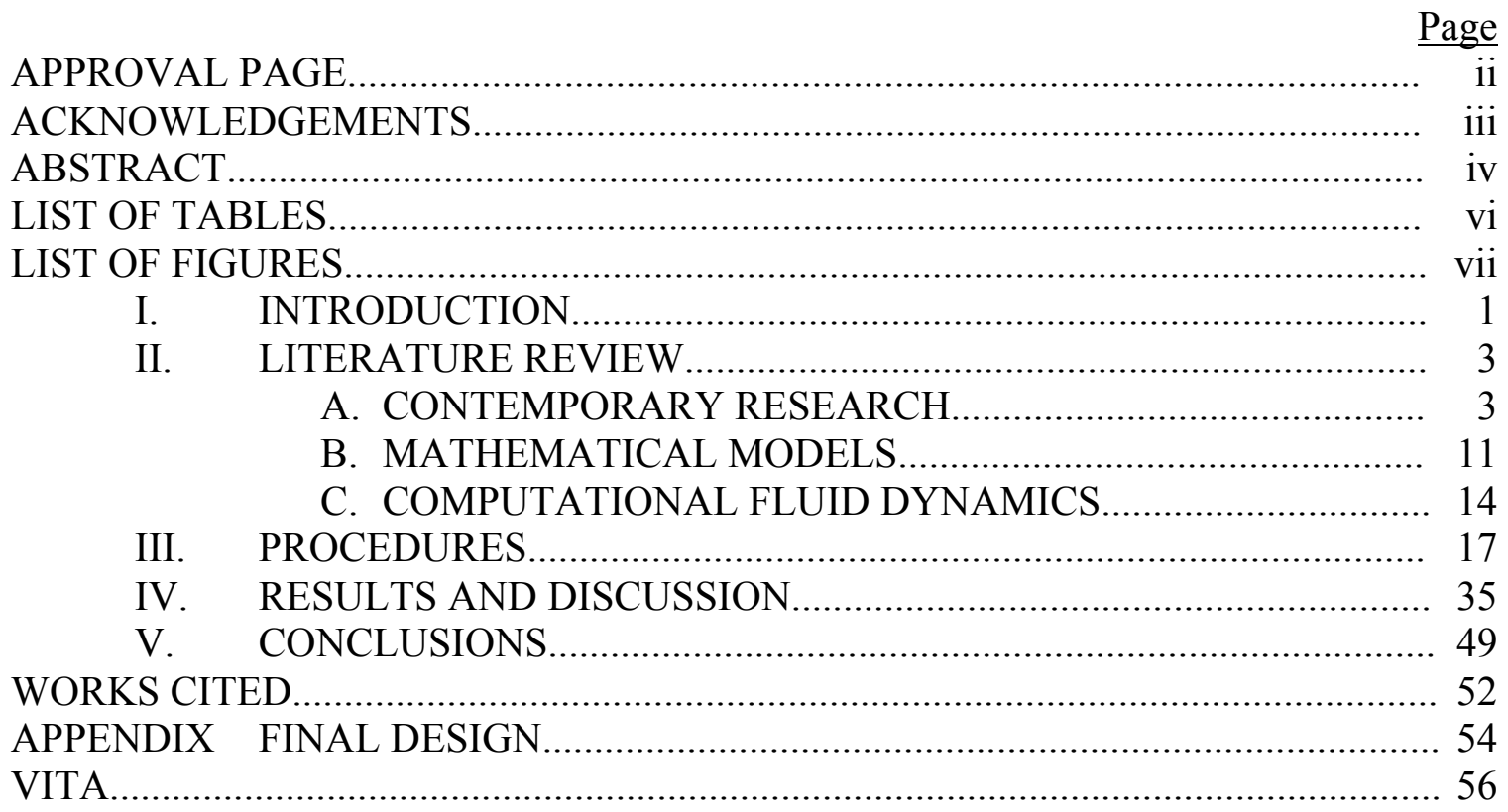




\section{TABLE OF TABLES}

Table

$\underline{\text { Page }}$

I. EXPLICIT COORDINATES FOR WIND TUNNEL .................................... 18

II. TOP THROAT SPEEDS AT VARIOUS INLET TIP CURVATURES........... 41

III. THROAT SPEED AT VARIOUS EXIT LENGTHS IN THE FINAL OPTIMIZATION STAGE 45

IV. THROAT SPEED AT VARIOUS CONE LENGTHS IN THE FINAL OPTIMIZATION STAGE 
TABLE OF FIGURES

Figure $\quad \underline{\text { Page }}$

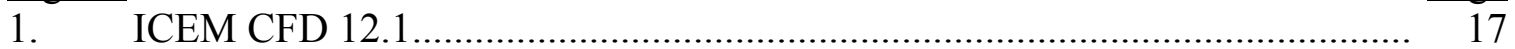

2. CREATE POINT BUTTON ...................................................................... 19

3. CREATE POINT BY EXPLICIT COORDINATES..................................... 19

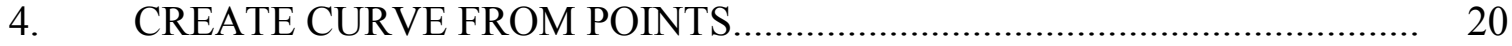

5. CREATE/MODIFY SURFACE BUTTON ................................................ 20

6. CREATE SURFACE OF REVOLUTION .................................................. 21

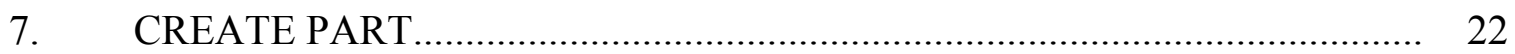

8. CURVE MESH SETUP BUTTON ............................................................ 23

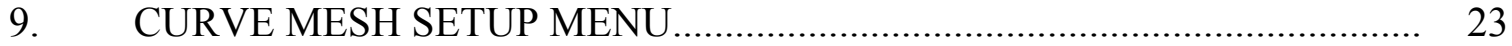

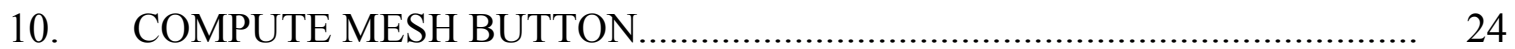

11. OUTPUT TO FLUENT V6 BUTTON ....................................................... 25

12. OPEN MESH BUTTON....................................................................... 26

13. SPECIFYING THE K-EPSILON TURBULENCE MODEL ......................... 26

14. CREATE/EDIT MATERIALS MENU ...................................................... 27

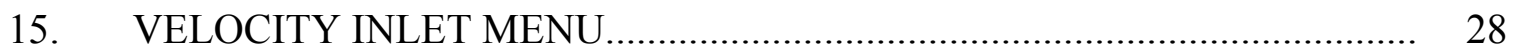

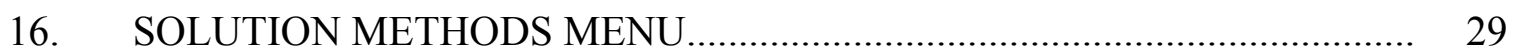

17. RESIDUAL MONITORS MENU …......................................................... 29

18. SOLUTION INITIALIZATION MENU ................................................... 30

19. RUN CALCULATION MENU............................................................... 31

20. CREATE PLANE SURFACE MENU ....................................................... 32

21. VIEW CONTOURS MENU ................................................................. 33

22. PROBE TOOL BUTTON ...................................................................... 33

23. VIEW VECTORS MENU...................................................................... 34

24. VISUAL REPRESENTATION OF CURVES 1-10. EACH CURVE WAS USED FOR THE PROFILE OF THE CONCENTRATOR INLET ................ $\quad 35$

25. TOP THROAT SPEED AS A FUNCTION OF CURVE NUMBER WHEN TREATED AS LAMINAR. CURVE NUMBER REFERS TO SAME DESCRIPTION AS IN FIGURE 24......................................................... 36

26. TOP THROAT SPEED AS A FUNCTION OF CURVE NUMBER WHEN TREATED AS TURBULENT. CURVE NUMBER REFERS TO SAME DESCRIPTION AS IN FIGURE 24

27. VISUAL REPRESENATION OF CONCENTRATOR INLET PROFILE INCLUDING CURVE AND CONE

28. RELATIONSHIP BETWEEN CONE LENGTH AND TOP THROAT SPEED WITHIN CONCENTRATOR

29. COMPARISON OF TURBULENT ENERGY $\left(\mathrm{M}^{2} / \mathrm{S}^{2}\right)$ BETWEEN SHORT CONE (LEFT) AND LONG CONE

30. RELATIONSHIP BETWEEN CONE WIDTH AND TOP THROAT SPEED WITHIN CONCENTRATOR.

31. COMPARISON OF TURBULENT ENERGY $\left(\mathrm{M}^{2} / \mathrm{S}^{2}\right)$ BETWEEN SHARP TIP (LEFT) AND ROUNDED TIP (RIGHT)........................................... 40

32. COMPARISON OF INLET TIP SHAPES................................................. 41 
Figure $\underline{\text { Page }}$

33. RELATIONSHIP BETWEEN EXIT LENGTH AND TOP THROAT SPEED WITHIN THE CONCENTRATOR........................................................... 42

34. PROFILE OF GAUGE PRESSURE WITHIN THE CONCENTRATOR. (PA) 43

35. COMPARISON OF GAUGE PRESSURE WITHIN CONCENTRATOR BEFORE (LEFT) AND AFTER ADDITION OF RELIEF SLITS. (PA)........... 44

36. COMPARISION OF TURBULENT ENERGY BEFORE (LEFT) AND AFTER ADDITION OF RELIEF SLITS. $\left(\mathrm{M}^{2} / \mathrm{S}^{2}\right)$. 44

37. VELOCITY VECTORS OF AIR THROUGH CONCENTRATOR. (M/S)...... 46

38. THROAT SPEED AS A FUNCTION OF INLET SPEED................................. 47

39. VELOCTY PROFILE THROUGH CONCENTRATOR WITH CYLINDRICAL CASING. (M/S). 48

40. VELOCITY VECTORS OF AIRFLOW THROUGH EXIT OF CYLINDRICAL CASING. (M/S). 48

41. DIMENSIONS OF FINAL CONCENTRATOR DESIGN AS SEEN FROM THE FRONT. (MM). 55

42. DIMENSIONS OF FINAL CONCENTRATOR DESIGN AS SEEN FROM THE SIDE. (MM) 54 


\section{INTRODUCTION}

As the United States continues to increase in population and develop in modernization, it is becoming increasingly desirable to expand the nation's energy supply. When this is combined with the instability and growing hostility with major fossil fuel providers in the Middle East, interest in alternative fuel sources has never been higher. The primary research has been in various areas of renewable energy sources, due to their potential long term reliability. Included in these are biomass, hydroelectric, solar, and wind power. While hydroelectric power remains the dominant source of renewable energy, wind power is increasing at the greatest rate.

Much of research and investment in wind power capacity has been aimed at the easier to harness high wind areas. Economic competition with other means of energy generation has meant that capturing energy from the low speed end of the spectrum (classes 1 and 2, <5.1 m/s at $10 \mathrm{~m}$ altitude) has been comparatively neglected. This is despite the fact that class 1 or class 2 wind conditions cover most of the United States.

The primary concern with low speed conditions is maintaining turbine rotation. In any turbine, the wind must maintain a certain minimum speed to force continued rotation of the blades. Below this minimum speed, friction within the generator exceeds the rotational force provided by the wind, and the blades forcibly halt. The wind must then exceed a higher velocity in order for the rotation to commence again. For lower classes of 
wind conditions, the fraction of time in which the blades rotate and generate power decreases. Thus, the operational uptime can drive down the economic feasibility of the device.

The purpose of this research was to test a wind concentrator for its ability to increase technical and economic feasibility of wind power in class 1 and class 2 conditions. This was accomplished via trials using computational fluid dynamics (CFD) to test several design features of the device. These features include entrance shapes to reduce turbulence, exit lengths, and post design analyses such as impacts of housing and performance at different speeds. The wind concentrator will ideally accelerate the air speed through a turbine by funneling wind from a larger cross section. By performing trials with CFD, many trials can be run in a short time frame and at low cost.

The first section of this thesis covers a summary of recent research in the field of low speed wind power generation. The next section describes the software and procedures used to complete the present research. Following this, the experimental results are presented, along with a detailed discussion and analysis of the data. Finally, conclusions will be drawn from the data, and recommendations for improvements and further research will be presented. 


\section{LITERATURE REVIEW}

\section{A. Contemporary Research}

Research and investment into low speed wind areas largely aims to reduce this minimum speed required for rotation, but ultimately all efforts aim to increase economic feasibility. The contemporary efforts can be broadly grouped into four main categories. First, improvements made to the aerodynamics of the blades attempt to create more lift, and therefore more spinning force. Secondly, gearbox and generator improvements attempt to reduce the internal friction resisting motion, while still capturing power. Thirdly, wind concentrators try to concentrate and speed up the wind before it reaches the turbine. Finally, some research is aimed at improving integration of wind power into the standard power grid, thereby making it cheaper and more cost effective.

A first approach at lowering the minimum wind speed and thus improving performance of wind turbines is to optimize the aerodynamics of the blades. Early attempts at this are diverse, with mixed results. For instance, a design patented by Fosdick features multiple rows of blades, similar to a jet engine (Fosdick, 1984). However, more recent research by the National Renewable Energy Laboratory (NREL) 
has much refined the optimal design of turbine blades, especially in terms of the airfoil shape. The basic airfoil shape recommended for low speed wind turbines by the NREL is a combination of the S822 and S823 airfoil designs. These have been the standard airfoil design since 1995. Since the acceptance of an optimized airfoil shape, more recent innovations have used this airfoil in the course of their design. A representative research by Zhang, et al. (2009) attempts to optimize the chord length and installation angle of the airfoil. They used the Hicks-Henne Function to develop a model blade modified from the previously accepted standard. From their modeling, they further optimized the blade to have a narrower, more circular chord in the blade root region. When this is combined with a monotonically descending installation angle as the blade extends radially, the blade performs significantly better in low speed conditions. For any tip speed ratio greater than the optimal value of 6 , their new model has a greater power coefficient than does the previously accepted design. Since the higher tip speed ratio indicates a lower wind speed, this refers to wind less than $5 \mathrm{~m} / \mathrm{s}$ at a rotation of $50 \mathrm{rpm}$ (Zhang, et al, 2009).

The most common approach to reduce the necessary minimum wind speed is to redesign the gearbox and generator apparatus. This is logical since these inner workings are the greatest source of friction and mechanical energy loss. Research into optimizing gear and electricity generation systems from low speed wind conditions includes booster mode controllers, specially designed variable speed generators, and magnetic bearings.

Calley and Knowler (2004) have developed a booster mode controller that allows wind turbines to generate power across a wide range of wind speeds. The boost mode controller allows regulation of rotation speed to prevent rotation that is too slow or too fast. Simply, the controller senses the voltage and current provided from the alternator. 
Working in tandem with a battery power supply, the controller will adjust the generator to slow down the blades if the rotation is so high that the system is near a stall. In this case, the generator is adjusted to provide more resistance, and so to absorb more of the mechanical energy from the blade rotation. The additional energy is stored in the battery, in part so that the power supplied to the grid does not surge, and in part so that the energy can be stored for low speed conditions. When the controller senses the rotation speed is too low and is thus close to seizing up and stopping, the battery actually supplies energy to the blades, so a minimum rotation speed can be maintained even when the wind speed is not fast enough to maintain operation. In this way, the machine can continue to operate without unnecessary downtime.

Fradella has developed a variable speed generator specifically designed for regulated current and voltage across a wide range of rotational speeds. This device attunes its resistance to the wind speed, and thus it can provide little to no resistance in low wind speed conditions. It senses the wind speed by measuring the angle on the rotors. This information is fed back into an integral power controller, which then outputs to the generator. The generator has a series of disks in the stator, each of which contain 2-phase stator windings (Fradella, 2009). Since each disk is a source of power generation, and thus a source of resistance, the power controller can vary the number of disks in operation. This is employed during system ramp up in such a way that the generator applies essentially no resistance, thereby reducing the minimum wind speed required to begin operation. This control is coupled with a variable braking mechanism for high wind speed conditions, so that the rotor does not turn faster than the generator can handle. Thus the device effectively extends the viable wind speed range in both the low and high-speed 
ends of the range. Though the inventor makes no specific quantitative claims regarding performance or minimum wind speed, the device is claimed to be an improvement upon previous older designs. (Fradella, 2009)

A design developed by Davis utilizes an ultra low friction system. This approach specifically examines the friction and resulting energy loss from the weight of the blade assembly upon the bearings. In this design, powerful rare earth magnets support a vertical axis turbine. The support mechanism via magnets means the weight of the turbine does not rest upon any point of metal-to-metal contact. With frictional force proportional to the normal force applied at a point of contact, the lack of turbine weight will greatly reduce the friction. In fact, in this design, normal operation of the turbine does not cause any physical contact between the rotating shaft and the generator stator (Davis, 2009), and so it is essentially a zero friction setup in that respect. By combining zero friction magnetic bearings with a generator that can accommodate low RPMs, the end result is a wind turbine that will operate with wind speeds below 5 knots (Davis, 2009). A limitation on this design is that it is applicable only for vertical axis wind turbines. Although it could conceptually be applied to the more common horizontal axis turbines, serious modifications would be required. Still, this design can lower the minimum average wind speed necessary for economic feasibility by increasing uptime in less windy conditions. This is certainly an improvement upon older style vertical axis turbines (Davis, 2009).

The next major method of improving wind turbine performance in low wind speed conditions is to utilize a wind concentrator. The wind concentrator is essentially a solid, static device that redirects airflow across the turbine blades. This, in effect, speeds up the air, as there is more wind flowing through a smaller space (Gagnon, 2010). The effect is 
similar to a constriction within a pipe, except in an open-air application; the wind has the option to redirect around the entire turbine and concentrator apparatus. Thus, the speed increase due to concentration must be balanced with the increased resistance to flow from redirection, or else the entire device will fail. Several different designs have been published for such devices.

A simple type of wind concentrator has been developed by Graham. This device is designed to take advantage of the preexisting geometry of buildings, with an additional mounted turbine on the roofline. When wind hits the vertical face of the side of a building, it redirects around it. Some of the wind will be diverted to the top of the building. At this point, the wind speed should be faster than the far-field speed, as the building face has concentrated it. Graham's design takes advantage of this preexisting concentrator that exists around all civilization. In this design a waterwheel type cylindrical turbine is placed at the roofline, with a lip placed over the edge of the roof, to redirect the now vertical wind coming up the side of the building. This design is better suited for small sized turbines, rather than for giant farm sized turbines. However, it is a simple design without requiring much development for implementation (Graham, 2006). Another style of wind concentrator acts as a wind inducer. A design by Tocher utilizes a series of concentrator blades immediately downwind of the turbine. These blades are circular, with a cross section shaped similar to an airfoil. The essence of the design is to pull more wind through the turbine via a pressure reduction within the inducer. As wind flows through the device, some passes through the opening for the turbine, while much more passes around it. All of this wind, whether it passed through or around the turbine, will pass through the inducer blades. The blades direct the wind 
outward, with a shape that concentrates and speeds it up. This speed increase should utilize Bernoulli's principle and create a lower pressure zone immediately following the outlet for the turbine. As a result, a disproportionate amount of the wind hitting the face of the device is drawn through the turbine opening, so that it might fill the pressure void at the outlet. The increased volume of air flowing through the confined space of the turbine chamber will necessarily be at a higher speed. In effect, the device induces faster wind speeds through the turbine than the far-field speed. With this speed increase, the minimum ambient wind speed required to maintain turbine operation is reduced (Tocher, 2004).

A design by Presz and Werle (2009) takes this inducer concept and expands upon it. In their device, the outlet funnel has added mixers and ejectors to improve the performance. As wind hits the device, it can travel into either the turbine stage or one of two outlet stages. In the outlet area, several rings of mixer lobes form a lower pressure region by accelerating the air moving through. This in turn pulls the air through the turbine chamber, thus increasing the power output from the generator. Unfortunately, in a device such as this, as the air slows down at the outlet, when it rejoins the far-field flow, it creates a mass of higher-pressure air. This forms a block that restricts flow through the entire device. The Presz and Werle design seeks to prevent this by installing a ring of ejectors towards the end of the device. These ejectors are holes along the exit shroud through which some of the air can exit. Thus as the air reaches the end and rejoins the farfield flow, some of the air has already left. This reduces the pressure buildup, and consequently reduces the resistance to flow through the device. The end result of the device is one that can maintain operation in lower wind speed conditions, in that the air 
coming in is accelerated by an induction effect. The negative effects of the induction are reduced by the ejectors, but the positive increase in the air speed through the turbine blades is not reduced.

A fourth major attempt at attaining economic feasibility and even creating profit from wind power is through various techniques for integrating turbines into the power grid. The current power grid is built heavily around supply from plants burning fossil fuels, such as coal or natural gas. The grid is currently poorly adapted to supply from less conventional sources like wind. High speed wind conditions can usually maintain a power supply similar to a traditional plant, but lower speed wind is not well matched to what the grid is established for. Current research is investigating various ways of remedying this issue.

One approach to solving this issue is presented by Forsyth, Tombari and Nelson (2004). They have studied the relationship between wind power and solar power, and have recognized a lot of similarities between photovoltaic power generation and small scale wind power generation. Through their research they have determined that these energy sources are very similar in terms of unit output, distribution and pricing (Forsyth et al, 2004). Additionally, the two products attract the same type of consumer, namely, the environmentally friendly money saver. Their solution for advancing wind power is to directly target consumers. Rather than generate power in a centralized location on a large wind farm, and then pay to transport the power to the consumers, a better option is to generate the power at the consumer. Since wind power does not carry with it substantial human input for operation, maintenance or cleanup, it would be ideally suited for use at a home or a business in a way fossil fuels would not be. As a result, the amount of 
operating time needed from the turbine can be reduced while still maintaining competitiveness, since distribution costs are reduced. Lower wind speeds can be economically competitive under such conditions.

Kirby and Milligan (2009), working for the NREL, have analyzed the effects of supplementing an already sufficient power grid with a wind farm, for the sake of conserving fuel or water that would otherwise be consumed by a fossil fuel plant. Their research focuses on capacity requirements between multiple regions supplied by the same power source. When power is generated in one location and delivered for consumption to another region, these regions are referred to as balancing regions. Each balancing region must maintain a certain available capacity during a given hour. This places the utility under legal obligation to maintain their capacity supply that they have promised from wind, even when the wind is not supplying enough energy. As a result, for the rest of the hour, the supplying region must provide energy to the other balancing region from their own conventional supply, even when the other balancing region has enough conventional supply to provide for itself (Kirby et al, 2009). By transporting conventional energy that could be generated locally, the supplying region must have a larger maximum generating capacity that they otherwise would not need, were they not sharing wind power with another region. The authors conclude that a grid infrastructure that can respond to demand more quickly (in so doing reflecting the quick response to wind changes) would eliminate this need for balancing with conventional power. By adapting the rules of the power grid to reflect the quicker response from wind power, additional cost need not be incurred, thus lowering the overall cost of wind power production and making it competitive in more conditions. (Kirby et al, 2009) 


\section{B. Mathematical Models}

In all natural processes, several simple, fundamental laws of nature define what does and does not occur. Among these are Newton's Laws of Motion, the Laws of Thermodynamics, and basic laws of conservation of energy and momentum. When one examines problems relating to flows, the most useful mathematical laws are the conservation laws. In the case of fluid flow around, across, and through solid objects, three major quantities are conserved: mass, momentum and energy.

The continuity equation determines the mass conservation in a system of flowing fluids. In its most basic form, the continuity equation is defined as (McCabe et al., 2005):

(Rate of mass flow in $)-($ Rate of mass flow out $)=($ Rate of mass accumulation $)$

This is simply a mass balance across the system. In essence, since matter can be neither created nor destroyed, any mass that goes into the system must either stay there or flow out of the system. Likewise, any matter coming out of the system must have either entered the system or been previously stored there. If one imagines the system as an arbitrary rectangular box with coordinates $\mathrm{x}, \mathrm{y}$, and $\mathrm{z}$, then the general mathematical form of Equation 1 becomes (McCabe et al., 2005):

$$
\frac{\partial \rho}{\partial t}=-\left[\frac{\partial(\rho u)}{\partial x}+\frac{\partial(\rho v)}{\partial y}+\frac{\partial(\rho w)}{\partial z}\right]
$$


where $\rho$ is the mass density, $\mathrm{t}$ is time, and $\mathrm{u}, \mathrm{v}$ and $\mathrm{w}$ are the respective velocities in the $\mathrm{x}$, $\mathrm{y}$ and $\mathrm{z}$ directions. Reorganizing terms and partial differentiation of Equation 2 yield (McCabe et al., 2005):

$$
\frac{\partial \rho}{\partial t}+u \frac{\partial \rho}{\partial x}+v \frac{\partial \rho}{\partial y}+w \frac{\partial \rho}{\partial z}=-\rho\left(\frac{\partial u}{\partial x}+\frac{\partial v}{\partial y}+\frac{\partial w}{\partial z}\right)
$$

Also crucial to consider is the momentum balance within the system. The NavierStokes equations define the momentum balance through the fluid, by applying Newton's second law to the forces acting upon and within the system. The resulting equation for motion in the $\mathrm{x}$ direction, for fluids of constant viscosity and density, can be expressed (McCabe et al., 2005):

$$
\rho\left(\frac{\partial u}{\partial t}+u \frac{\partial u}{\partial x}+v \frac{\partial u}{\partial y}+w \frac{\partial u}{\partial z}\right)=\mu\left(\frac{\partial^{2} u}{\partial x^{2}}+\frac{\partial^{2} u}{\partial y^{2}}+\frac{\partial^{2} u}{\partial z^{2}}\right)-\frac{\partial p}{\partial x}+\rho g_{x}
$$

where $\mu$ is the viscosity, $\mathrm{p}$ is the system pressure, and $\mathrm{g}_{\mathrm{x}}$ is acceleration due to gravity in the $\mathrm{x}$ direction. The assumption of constant density and viscosity is valid for liquids and for gases at low velocities. Similar equations exist for motion in the $\mathrm{y}$ and $\mathrm{z}$ directions.

The final conserved quantity to consider is energy. From the outset, energy within the system can be viewed in terms of a mechanical energy balance. The general mechanical energy terms to consider are the pressure, elevation and velocity within the system. Thus the basic energy balance, called the Bernoulli equation, becomes (McCabe et al., 2005): 


$$
\frac{p_{a}}{\rho}+g Z_{a}+\frac{u_{a}^{2}}{2}=\frac{p_{b}}{\rho}+g Z_{b}+\frac{u_{b}^{2}}{2}
$$

where $\mathrm{Z}$ is elevation and $\mathrm{a}$ and $\mathrm{b}$ denote initial and final conditions, respectively. Equation 5 describes the energy balance in open, laminar flow apart from any solid components, thus eliminating the effects of friction. In reality friction is a significant term. Since the frictional effects on the mechanical energy balance are simply a conversion of mechanical energy to thermal energy, the Bernoulli equation can be modified to (McCabe et al., 2005):

$$
\frac{p_{a}}{\rho}+g Z_{a}+\frac{u_{a}^{2}}{2}=\frac{p_{b}}{\rho}+g Z_{b}+\frac{u_{b}^{2}}{2}+h_{f}
$$

where $h_{f}$ represents the heat generated via frictional losses.

The most significant source of friction within a fluid system is flow turbulence. The most generalized forms of the Navier-Stokes equations include the shear stresses within the fluid due to different sections of the stream sliding past each other, and thus account for the effects of turbulence and friction. However, these are impractical for general use. Consequently, numerous turbulence models have been developed. These are essentially one or several governing equations in addition to those above that account for the effects of turbulence. The addition of these relatively simple equations obviates the need for using overly complex versions of Navier-Stokes. While there are many different models, each of which has its own advantages and disadvantages, the most common 
model is the Standard K-Epsilon Model, developed by Launder and Sharma. This model adds two additional turbulence parameters: $\kappa$ and $\varepsilon . \kappa$ represents the kinetic energy of the turbulence, while $\varepsilon$ represents its dissipation rate. This model is most accurate in settings with small pressure gradients opposing flow. (Launder et al, 1974)

Using the continuity equation, Navier-Stokes equations, Bernoulli equation, and possibly additional turbulence modeling equations, one can accurately model the flow of a fluid through a system. For anything but the simplest flow scenarios, application of these equations can become quite cumbersome. Consequently, researchers will commonly employ computers to perform these analyses for them. This introduces the concept of computational fluid dynamics, which is discussed in the next section.

\section{Computational Fluid Dynamics}

While the general concept of fluid flow is fairly straightforward, applying it mathematically to actual scenarios is often exceedingly difficult. Models that are not overly cumbersome have been developed to describe certain narrow, specific situations, but even these are often only accurate to $25 \%$ (Incroprera, et al, 2007). Consequently, accurate modeling of complex flow scenarios requires intensive calculations. These calculations are part of a field called computational fluid dynamics (CFD).

The field of CFD is a relatively new addition to science and engineering. Prior to the 1970 's, there was no means of modeling fluid behavior through a system of any complexity without actual empirical trials on models. The complicated nature of the 
mathematical analysis made performing the necessary calculations to make predictions impossible to do by hand. It was simply too time consuming to perform with any useful level of robustness. Since such robust calculations are intensive to solve, powerful computer processing (such as with super computers) is necessary to find a solution. As computer technology has become more prevalent, cost efficient, and powerful over the past several decades, the use of CFD calculations has correspondingly become more feasible. Even with the best supercomputers of today, these problems can take days of non-stop calculating to solve. So how does a computer solve a CFD problem within a reasonable amount of time?

Achieving a solution begins in a CFD software package, such as Fluent or OpenFOAM. These software packages work with a complex geometry by examining it on a micro scale in a collection of small computational cells with simple geometric shapes. These collections are called meshes. A mesh can be created in the CFD package or a compatible geometry creation program. The mesh cells effectively allow the CFD software to take a complicated geometry for which there are no developed models and turn it into thousands or even millions of simple scenarios for which there are welldeveloped models. Given a set of initial and boundary conditions for the overall model, the solver will iterate through each cell to match the cell boundaries together. It will continue this process until a steady state is achieved, or else for a specified number of iterations for a steady state solution.

Each cell is a simple two- or three-dimensional shape, such as a tetrahedron. Heat and mass transfer characteristics, such as velocity vectors, temperature, and density, are analyzed across each cell. For the sake of calculation, the fluid is treated as homogenous 
within each cell. With a large number of cells within the mesh, this becomes a good approximation. When cells abut walls or other similar boundaries, the boundary condition can be fixed to match the known conditions at that point. Through this process, a largescale fluid flow problem through or across a solid piece can be accurately modeled.

CFD use has been a boon to science and engineering research. Through computer modeling, researchers can perform many trials on designs in a short span of time. Thus saving time and money compared to having to build and test many physical models and prototypes during the optimization process. In this way CFD has made developing engineering applications more efficient and effective. 


\section{PROCEDURES}

The software used for mesh generation was Ansys' ICEM CFD 12.1 (Figure 1).

This program is designed for compatibility with CFD modeling software. The software is

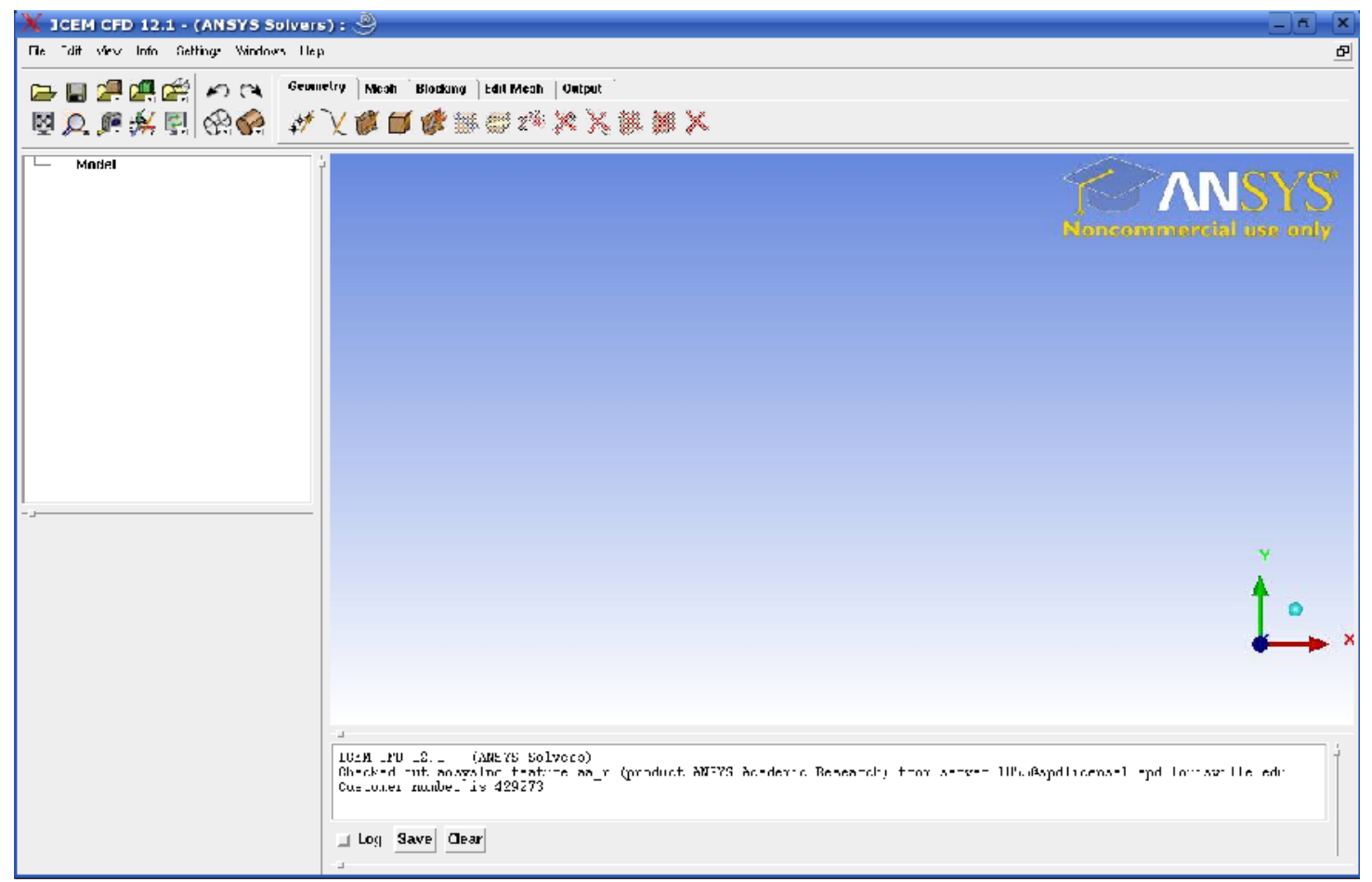

Figure 1: ICEM CFD 12.1 
capable of geometry modeling and mesh generation. Meshes can be either an unstructured tetrahedral mesh or a structured hexahedral mesh. Upon generation, ICEM can generate an output file compatible with Fluent or several other CFD engines.

To accurately model the wind concentrators, the device was modeled in free stream conditions by creating a simulated wind tunnel around the concentrator. The size of the wind tunnel was chosen to allow for sufficient clearance from the walls on all sides. Since all geometry on the concentrator was radially symmetrical, the tunnel was designed as a cylinder, and geometry for both tunnel and concentrator were initially modeled as 2D cross sections. These cross sections were then rotated around a $360^{\circ}$ axis to create $3 \mathrm{D}$ bodies.

To begin, open ICEM to a new project. Click the geometry tab at the top and select "Create Point," as seen in Figure 2. This will open a menu on the left side bar. In this new menu (Figure 3), select "Explicit Coordinates." Using this option, create points

\begin{tabular}{llll}
\multicolumn{2}{l}{ Table I: Explicit Coordinates for Wind Tunnel } & \\
Point Number & x-coordinate & y-coordinate & z-coordinate \\
1 & -4.5 & 0.5 & 0 \\
2 & -4.5 & 4.5 & 0 \\
3 & 5.5 & 4.5 & 0 \\
4 & 5.5 & 0.5 & 0
\end{tabular}

according to Table I. The resulting rectangle is designed such that the corner of the concentrator will be situated at the origin.

The rectangular set of points need next to be bounded by a series of curves. On the geometry tab, click "Create/Modify Curve," as in Figure 4. On the side bar, the "From Points" option will allow the points to be connected. Left click on point \#1 and then point 
$\# 2$. By middle clicking, the curve will be created. Repeat the procedure to connect $\# 2$ to $\# 3$ and $\# 3$ to $\# 4$. If more than two points are selected before the selection is confirmed by

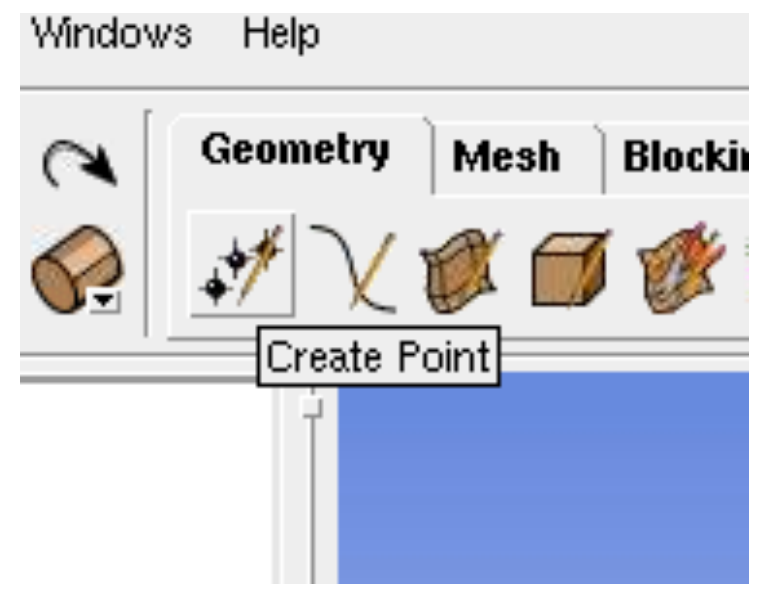

Figure 2: Create Point Button

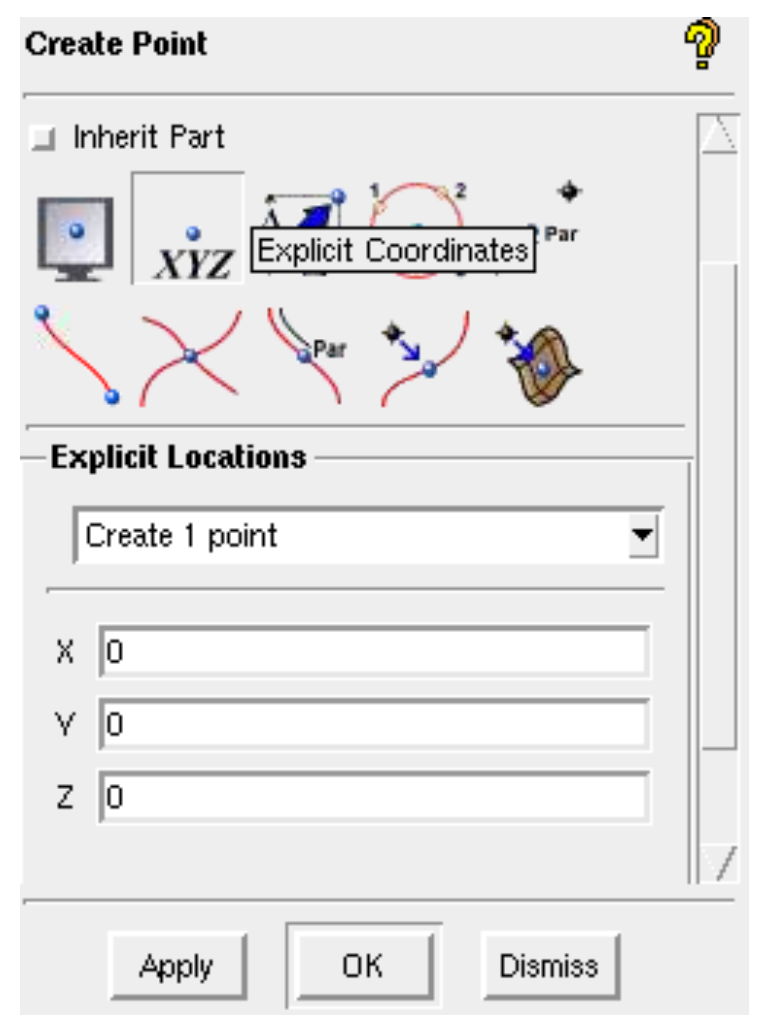

Figure 3: Create Point by Explicit Coordinates

a middle click, ICEM will generate a smooth curve to fit through all of the selected points. 
Next needed is the geometry of the concentrator device. The tools described above can be used to generate all the curves used in the profiles of the concentrators tested. Most concentrator designs employed curves defined by 10 points for the inlet

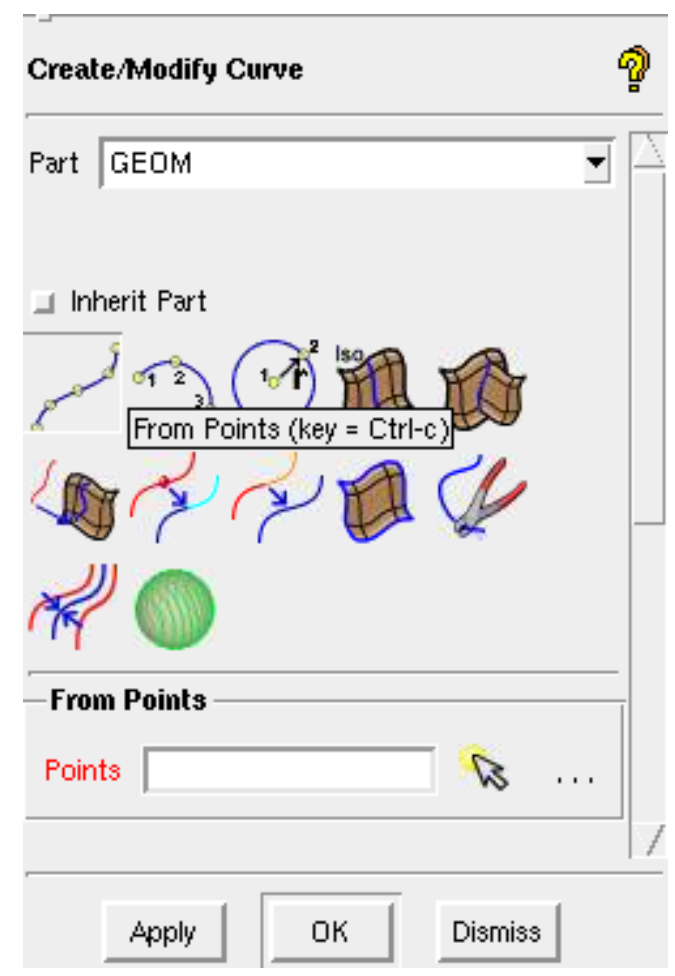

Figure 4: Create Curve from Points

section, as well as separate lines and points for the throat, exit and cone sections. More complicated inlet designs utilized additional points.

The goal behind creating the half profile is to allow for the creation of a surface of revolution. In this idea, the profile will be rotated around its base (as the axis) for $360^{\circ}$, such that a solid, 3D form is created. To do this, press the "Create/Modify Surface" 


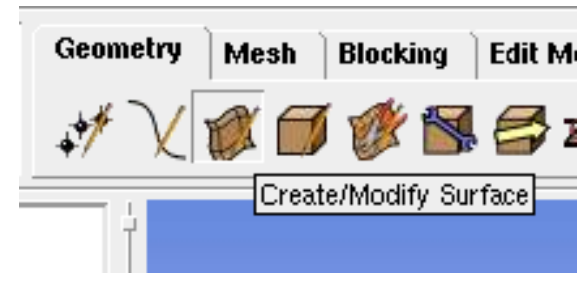

Figure 5: Create/Modify Surface Button

button (Figure 5) upon completion of the profile design. Choose the option "Surface of Revolution" on the left pane (Figure 6), and then select 0 and 360 for the start and end angles, respectively. For axis points, select points \#1 and \#4. When selecting curves to rotate, either manually select each curve, or more simply use a click and drag method to create a selection box around all the curves. Then, center click to confirm the selection.

At this point the geometry has been fully created. The next tasks are to prepare the model for CFD processing in Fluent. These include specifying boundaries, meshing, and exporting.

To specify the boundaries, the inlet and outlet faces of the wind tunnel cylinder need to be assigned to separate parts. In this way Fluent can interpret them as separate boundaries from the wall of the tunnel or from the surfaces of the concentrator. On the left menu, use the right click to select "Parts." Then, from the drop down menu, select "Create New" (Figure 7). Specify a name for this part that is indicative of its purpose. Since the part will represent the air inlet, a name like "Inlet" will suffice. Then select the entity, namely, the cylinder face on the inlet side of the device. Selecting "Apply" will create the desired part. In the same manner, a part should be created specifying the outlet face. 


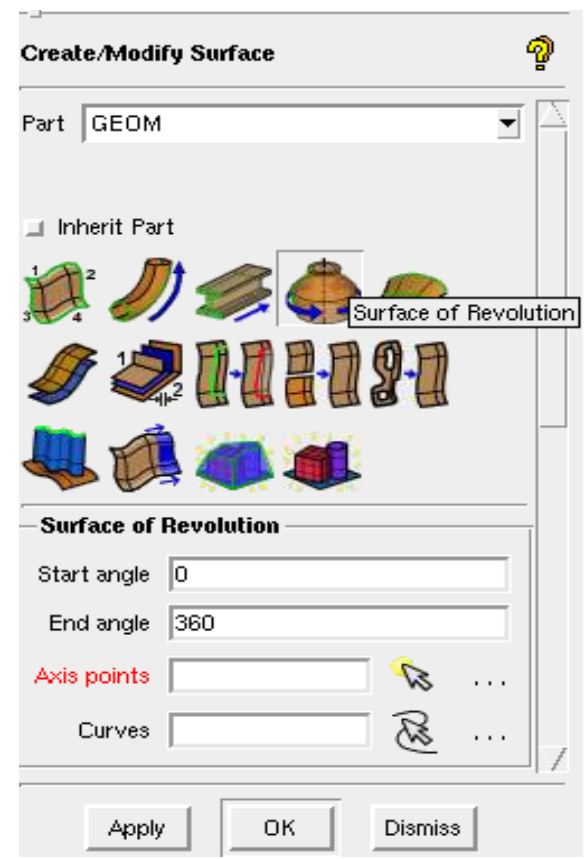

Figure 6: Create Surface of Revolution

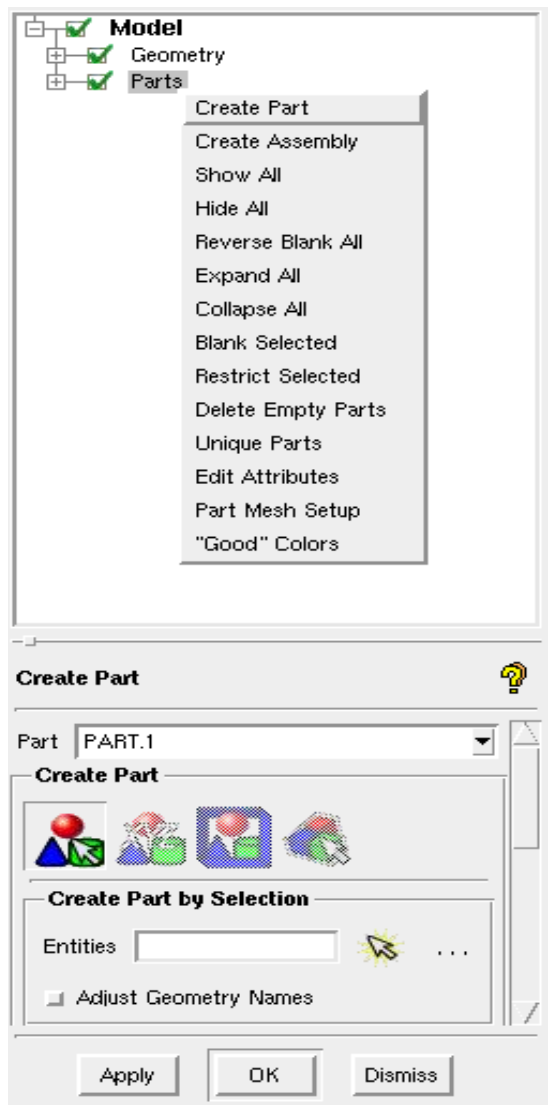

Figure 7: Create Part 
The next step is to create the mesh around the geometry. The mesh discretizes the model into a finite number of computational cells, which can then be used for numerically solving the equations of fluid motion in Fluent. The first step in creating the mesh is to define the mesh density. For the trials detailed in this thesis, the tool used is the "Curve Mesh Setup" tool (Figure 8). This is found on the "Mesh" tab. In this tool, a

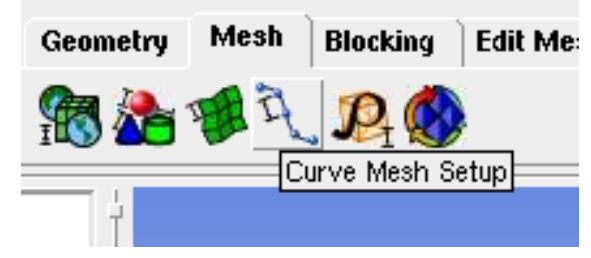

Figure 8: Curve Mesh Setup Button

set number of nodes can be assigned to a specific curve, or else to each in a set of curves. Using this feature, the number of nodes should be set higher for curves around which a more precise calculation must be obtained. As such, the curves defining the wind tunnel

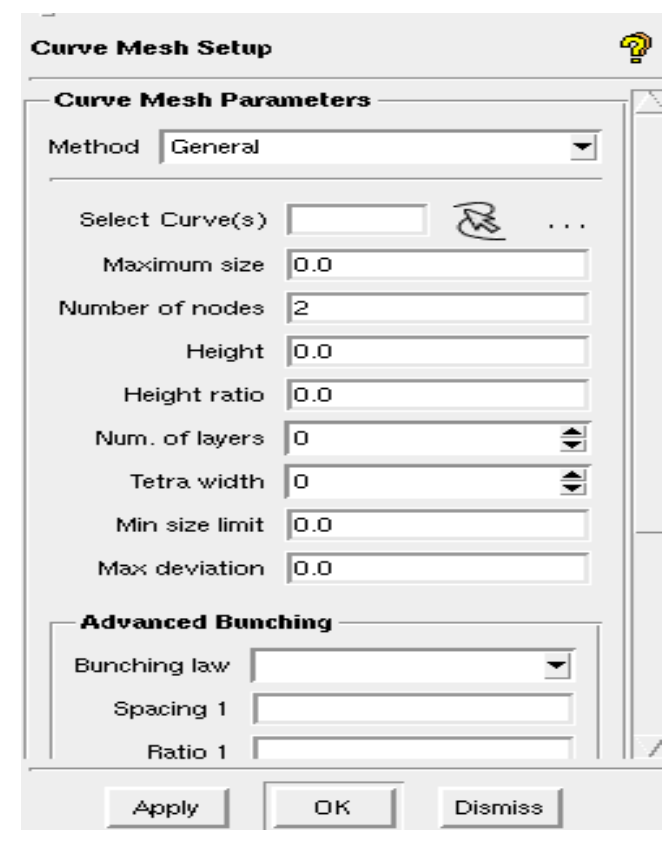

Figure 9: Curve Mesh Setup Menu 
require a much lower mesh density than do those within the concentrator. Once the curve mesh density is specified, click the "Compute Mesh" button on the Mesh tab (Figure 10), and then press "Compute" on the left sidebar. At this point ICEM will create a 3D mesh model around the geometry.

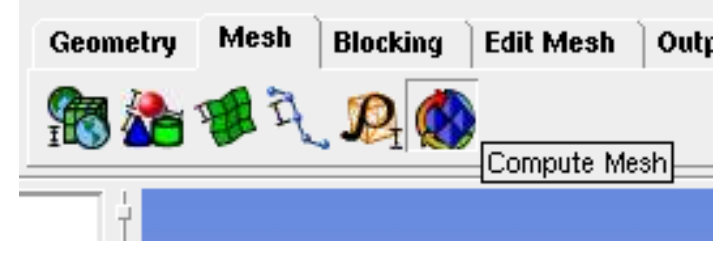

Figure 10: Compute Mesh Button

After geometry is created, it should be evaluated for consistency and size. The mesh should be checked to ensure that it consistently represents the underlying geometry. Occasionally, especially on thin parts, the mesh will leave holes in the geometry, or else incompletely mesh the extent of the thin sections. To remedy this, the mesh density in that region should be increased, perhaps by increasing the number of nodes along the characteristic curves of the feature, and then re-computing the mesh. Also important to pay attention to is the total cell count. A higher number will generate a better result in Fluent, but will also create larger files and require more computational time. Furthermore, some licenses for Fluent have a maximum allowable cell count of 512,000. For the models described herein, all mesh counts were about 500,000.

If the mesh is satisfactory, then it is ready to export to Fluent. It is advisable to save the project file at this point. Following that, select the "Output" tab at the top bar. Under this tab, select the "Fluent V6" button (Figure 11). Here it will possibly prompt 


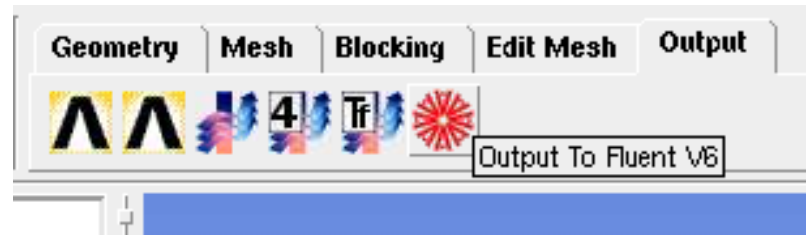

Figure 11: Output to Fluent V6 Button

about saving the file, followed by a window about "Family Boundary Conditions." These should be correct, and so click "Accept." Next it will ask the user to select file for output. ICEM will have created a .uns file with the same file name as the project file. The .uns file represents the mesh file, and so it is the needed file for output. Select this file. Then the final window will ask about $2 \mathrm{D}$ versus $3 \mathrm{D}$ modeling, as well as scaling factors on the mesh, and finally the output file name. Name the file for easy access in Fluent. When you select "Done," the file will be prepared as a Fluent .msh file.

Having created a .msh file in ICEM, subsequent tasks are completed in Fluent. For the trials described herein, the software used was Ansys Fluent 12.1.2. The .msh file must be converted to a Fluent .cas file. In the process, the fluid dynamics of the problem will be specified. As the .cas is prepared, boundary conditions are defined, as well as settings like turbulence models and equations of state.

To continue, open the 3D version of Fluent. Import the .msh file by clicking the folder icon at the top, and choosing "Mesh" (Figure 12). Select the correct file and allow Fluent to import. After importing, Fluent will display the mesh on the main screen. From here, the left pane menu ("Problem Setup") will guide the process roughly in order. Select "Models" and double click "Energy." Check the box to turn the energy equation on, and then click 'Ok." Below "Energy, select "Viscous." Here the turbulence model 


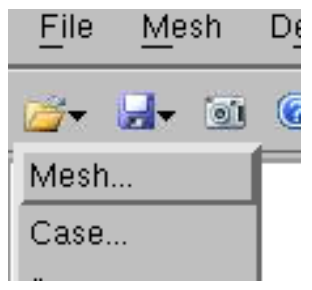

Figure 12: Open Mesh Button

(if any) can be specified (Figure 13). For these trials, select 'k-epsilon (2 eqn)" and retain

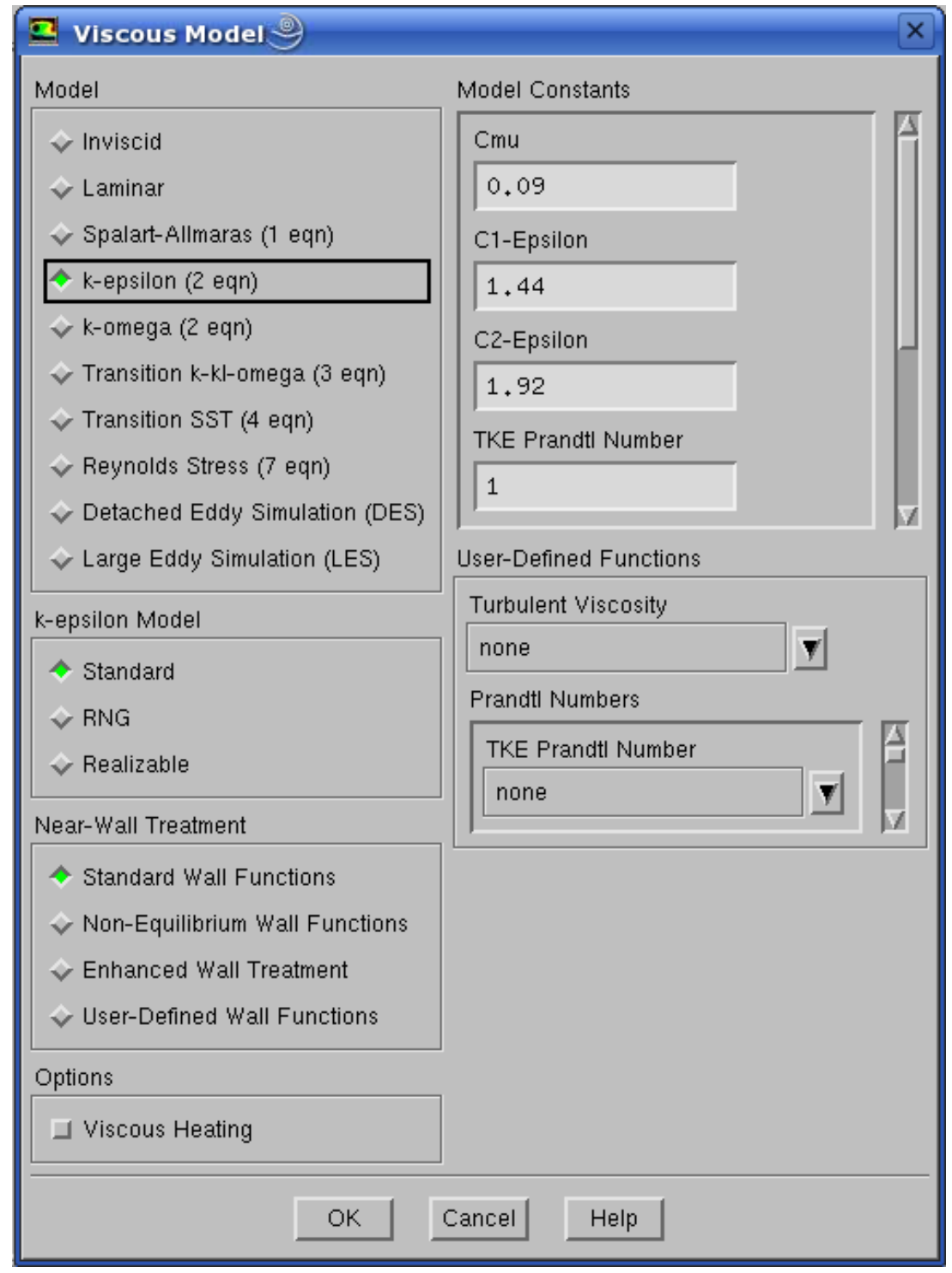

Figure 13: Specifying the k-epsilon Turbulence Model 
the default selection of "Standard" model and "Standard Wall Functions" in the bottom box. Click "Ok" to continue.

Return to the "Problem Setup" menu and click "Materials." This menu allows creation or modification of the different fluids and solids used in modeling. Select "Air" under the Fluids section. Under the "Density" section, use the drop box to choose "Ideal Gas." Since the system models atmospheric conditions, the ideal gas law will accurately model changes in density and pressure due to wind flow. Click "Create/Modify" to retain the selection (Figure 14).

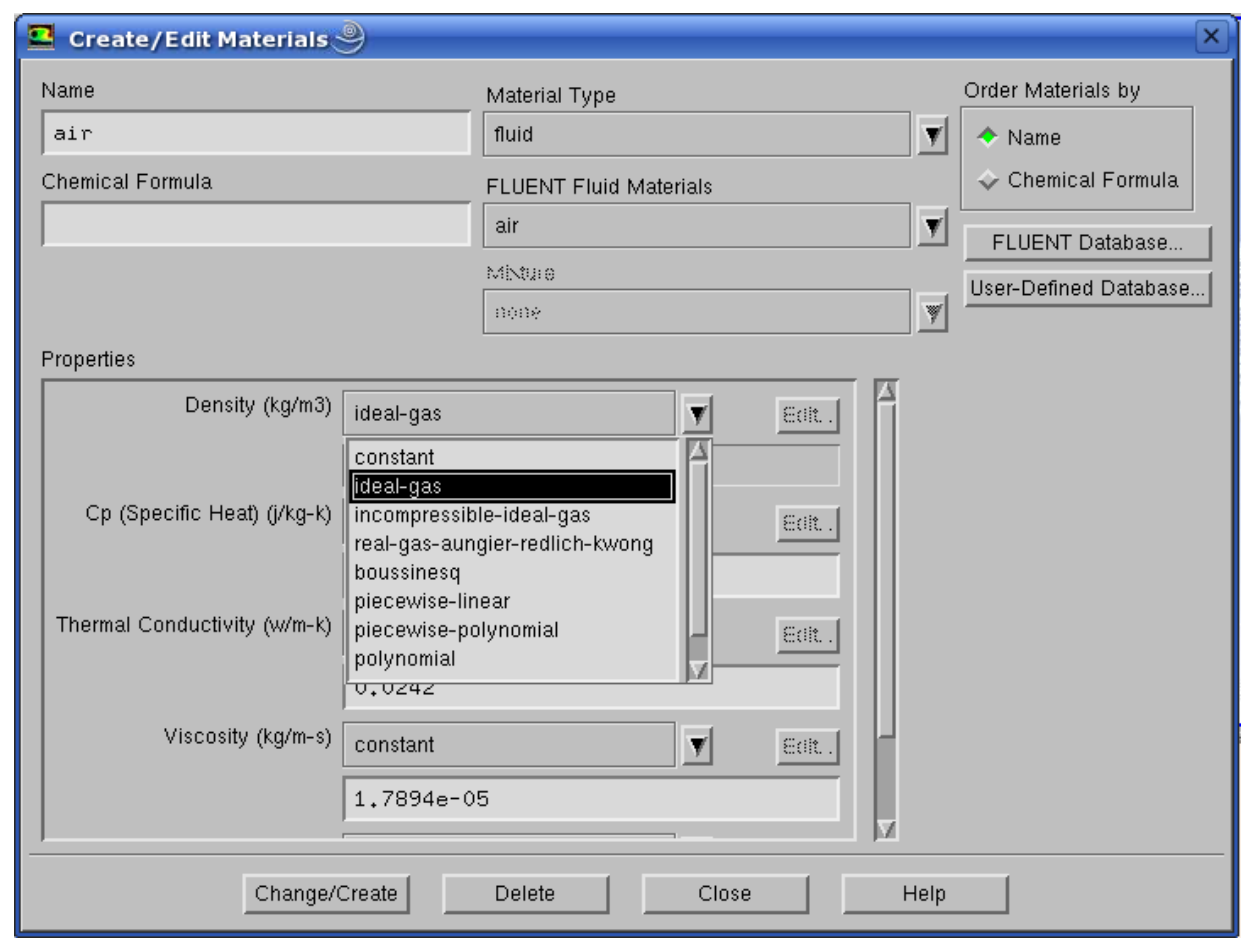

Figure 14: Create/Edit Materials Menu

The next settings to adjust are "Boundary Conditions." Here, the inlet face of the wind tunnel can be selected by whatever name was chosen above. Then, below the selection pane, use the drop box to select "Velocity Inlet" (Figure 15). When asked if it is 
OK to change the boundary condition, select "Yes." Under inlet velocity, specify $2 \mathrm{~m} / \mathrm{s}$ (or any desired test velocity). Click OK, and then select the outlet face. Here

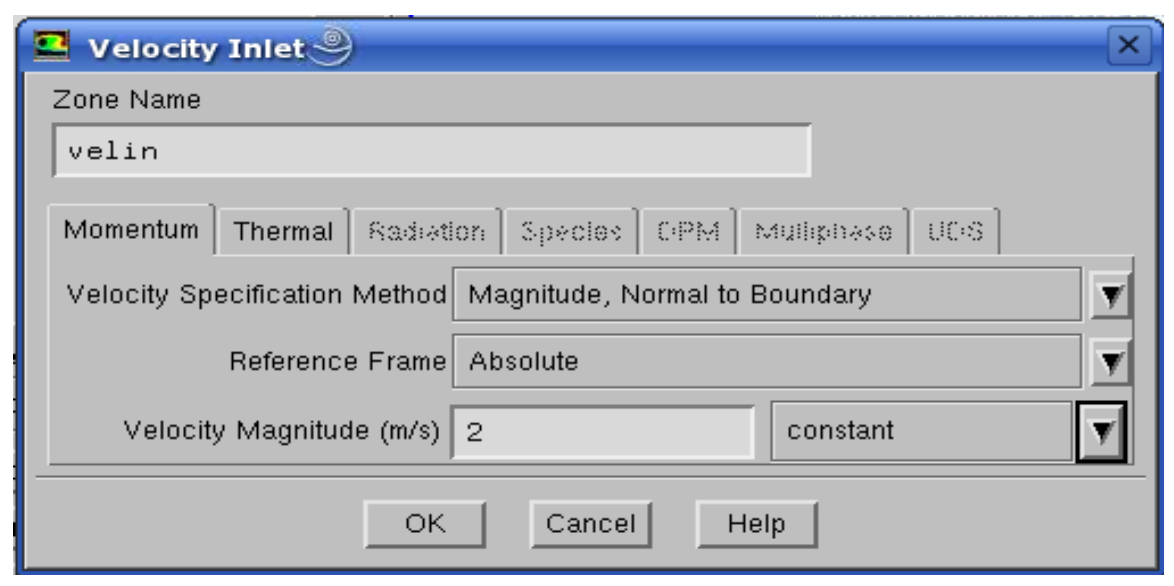

Figure 15: Velocity Inlet Menu

the type should be "Pressure-outlet. The default settings should suffice, so click OK to confirm. All other boundaries should be set as "Wall."

Back on the left pane, select "Solution Methods" (Figure 16). In this sub menu the "Scheme" box should be changed to "Coupled." This will change the available options under the "Spatial Discretization" section. Gradient should be set to "Least Squares Cell Based," under Pressure "Second Order" should be chosen, and all other options should be set to "Third-Order MUSCL." This will ensure a robust calculation.

Below Solution Methods, the next step is under "Monitors." Here, double click on "Residuals - Print, Plot" (Figure 17) to alter the convergence criteria. Next to each residuals option, the value under Absolute Criteria should be set to 0.00001 (or 1e-05). This will ensure that iterations will continue until calculations have reached a high level of convergence. 


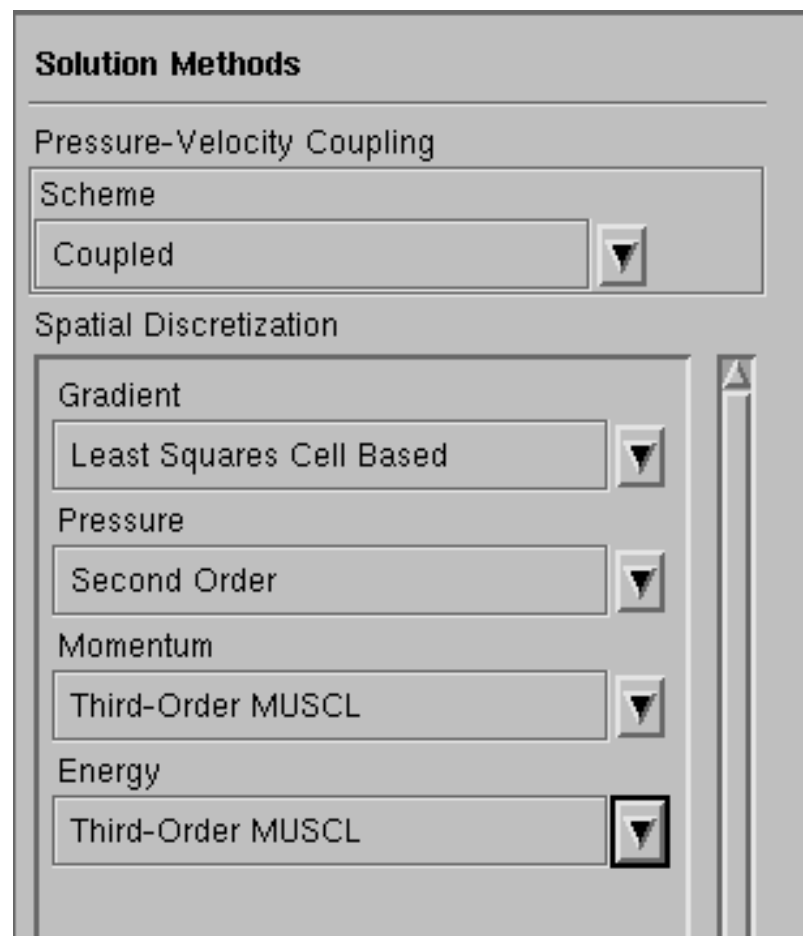

Figure 16: Solution Methods Menu

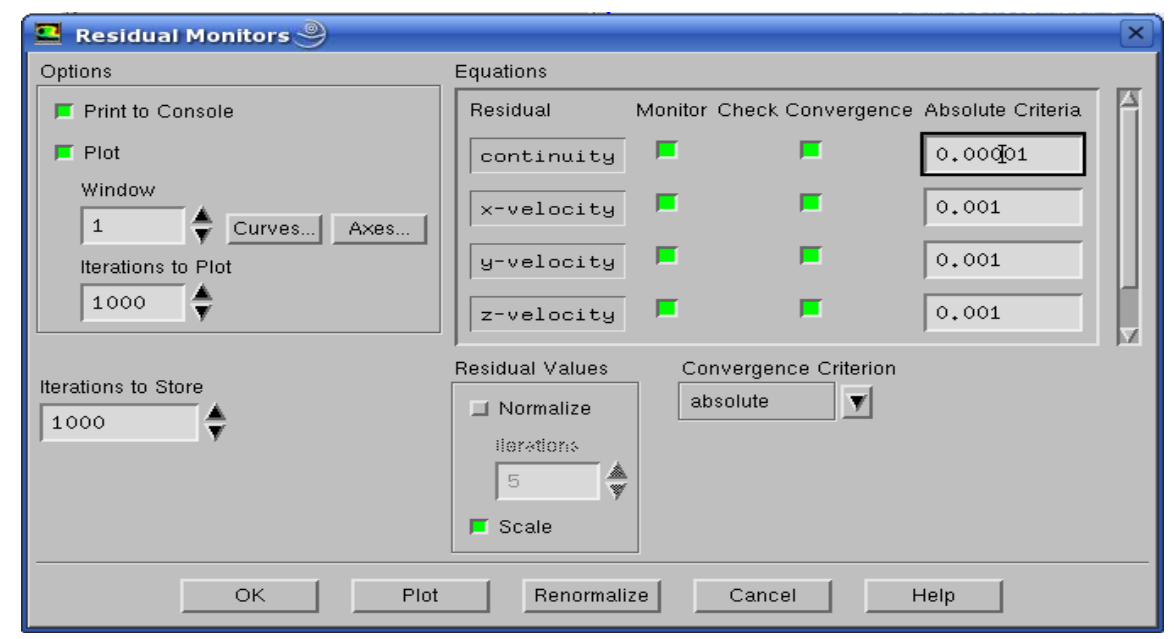

Figure 17: Residual Monitors Menu

The final step in preparing the case to run in Fluent is to initialize the data. This is completed under "Solution Initialization" on the left (Figure 18). Pressing the button labeled "Initialize" will assign initial values for velocity and other components to all the 


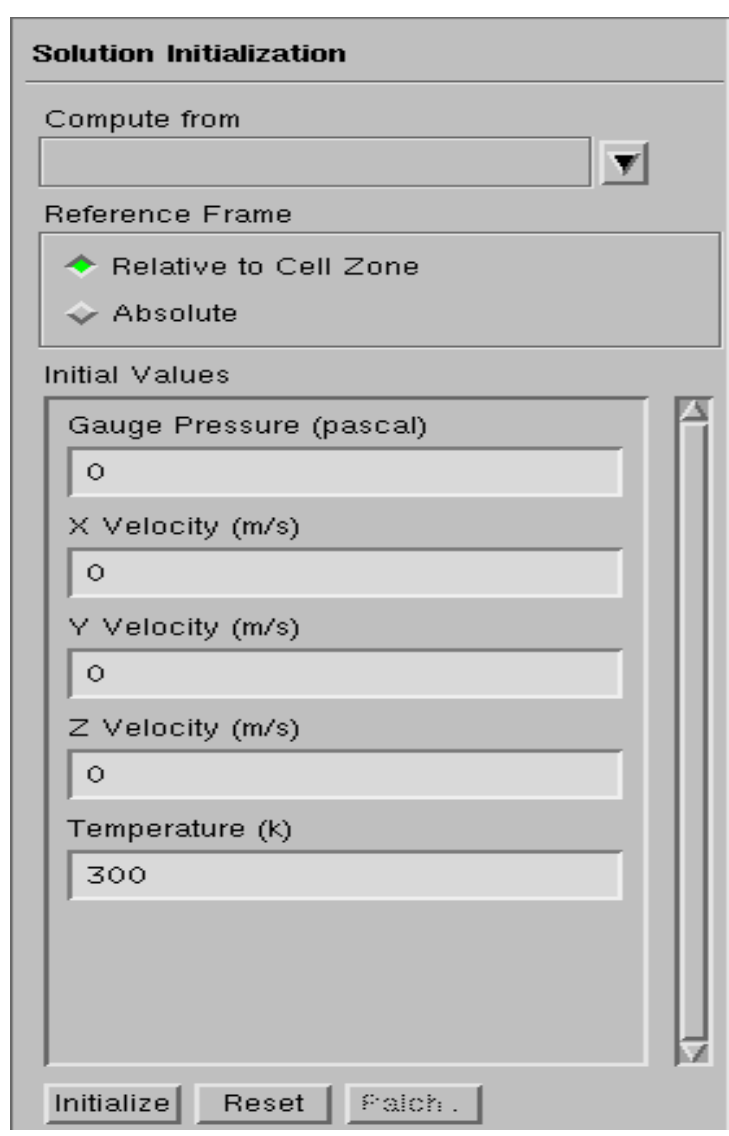

Figure 18: Solution Initialization Menu

cells in the mesh. This will allow for iterative calculation to commence. At this point, since the case and data files are setup and ready for analysis, it is advisable to save. Click the Save icon, and select "Case and Data." Give an appropriately descriptive file name, and click OK.

The case is ready to run. If the server system is set up to handle batch file input, that should be performed now. Otherwise, click "Run Calculation." Input the desired number of iterations (500-1000 is a good range to start), and then click "Calculate" (Figure 19). 
After the solver has completed the requested iterations (or, more preferably, reached convergence), the data can be analyzed in post processing. The options on the left pane of interest are under the "Results" section. Select the "Graphics and

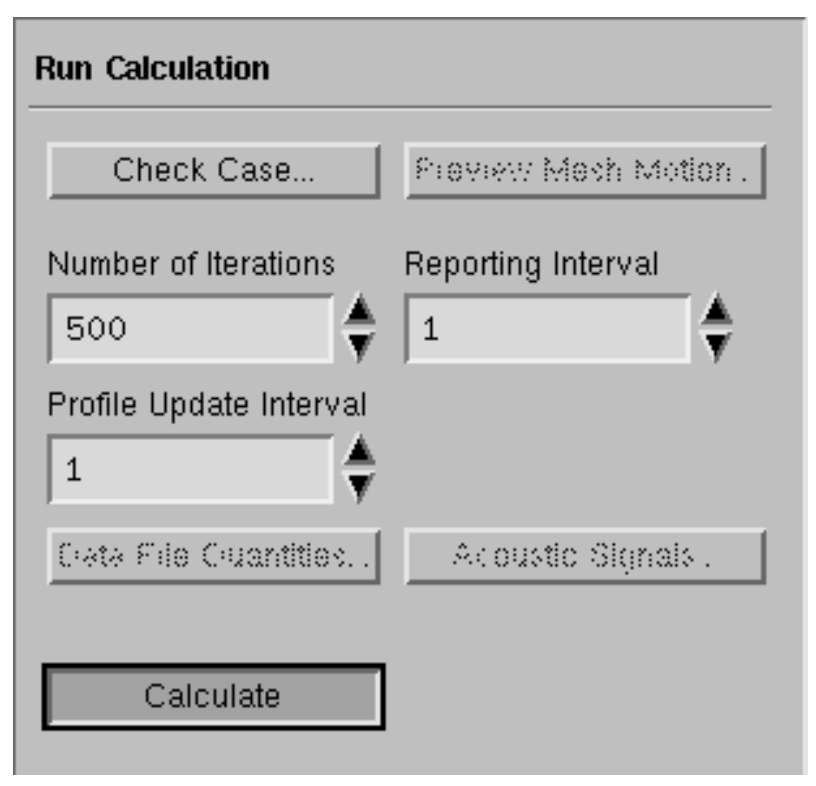

Figure 19: Run Calculation Menu

Animations" option. The two most relevant features are the "Contours" and "Vectors" options in the Graphics section. Double click Contours and examine the pop up window. Make sure that "Filled," "Node Values," "Global Range" and "Auto Range" are checked. Select the desired value to examine using the drop boxes under "Contours of." It is also beneficial to change the value under "Levels" to 100. Lastly, define the surface across which to view the contours. Do this by clicking "New Surface," and then clicking "Plane." This window (Figure 20) will allow the user to create a plane of viewing by specifying three non-colinear points on the plane. For this model, it is convenient to create a cross section along the xy-plane, and so choose $(0,0,0),(1,0,0)$ and $(0,1,0)$. Name 


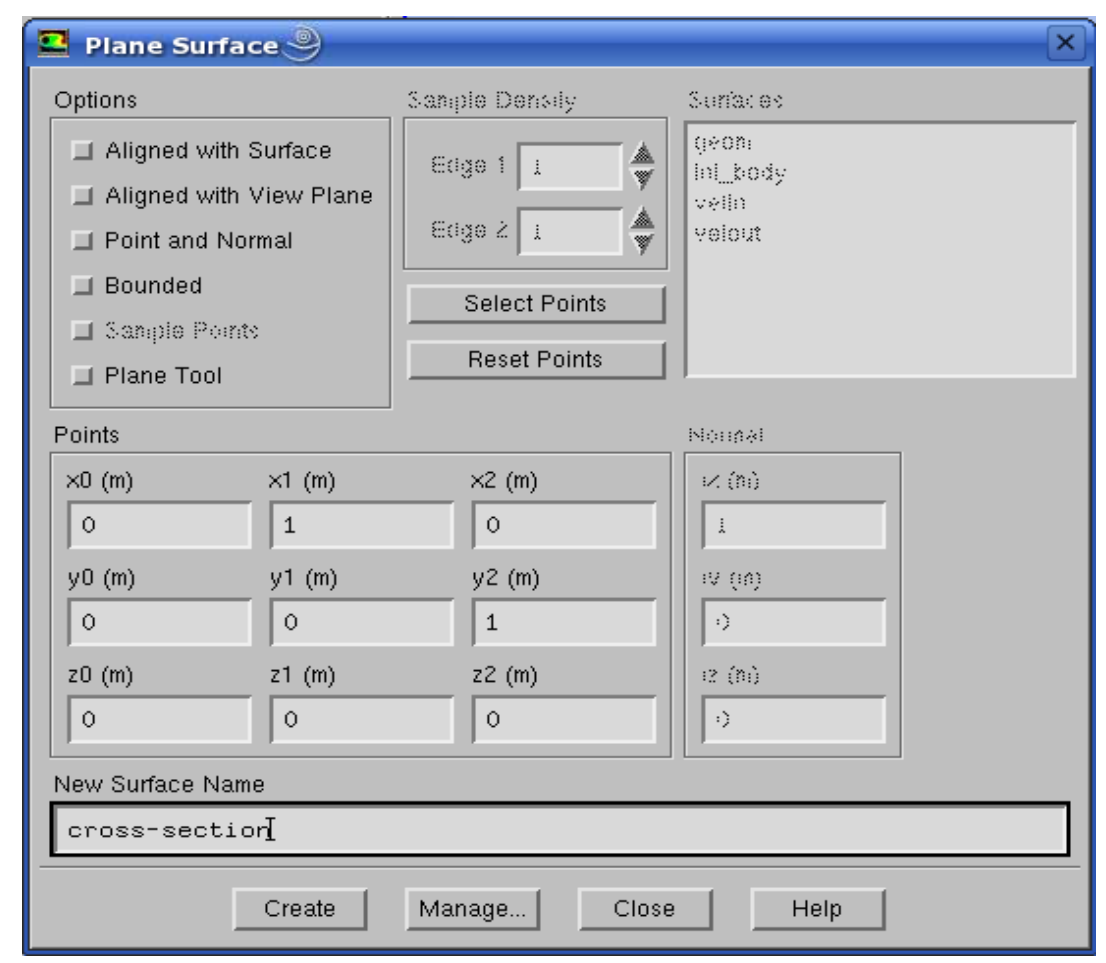

Figure 20: Create Plane Surface Menu

this plane something descriptive, and then click "Create." Now choose this plane under "Surfaces" and click "Display" (Figure 21). Using the probe tool, the value in specific cells can be read (Figure 22).

After viewing the desired contours, the vectors of velocity can also be useful. Double click "Vectors" and choose the previously created surface for viewing (Figure 23). Also select "Velocity" under "Vectors of" and "Velocity Magnitude" under "Color by." Again, the probe tool can be used to read values in specific cells. 


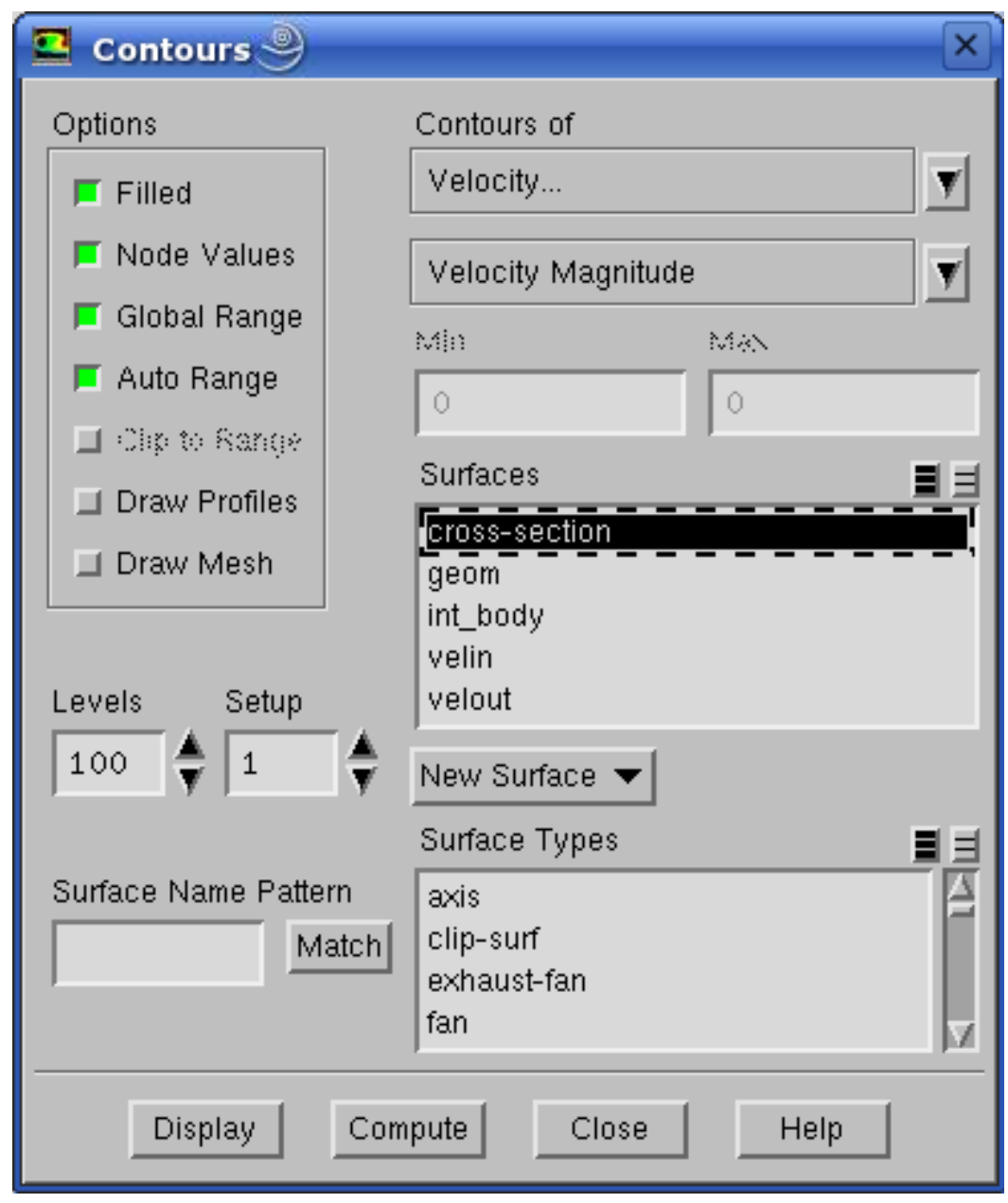

Figure 21: View Contours Menu

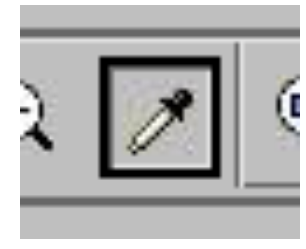

Figure 22: Probe Tool Button 


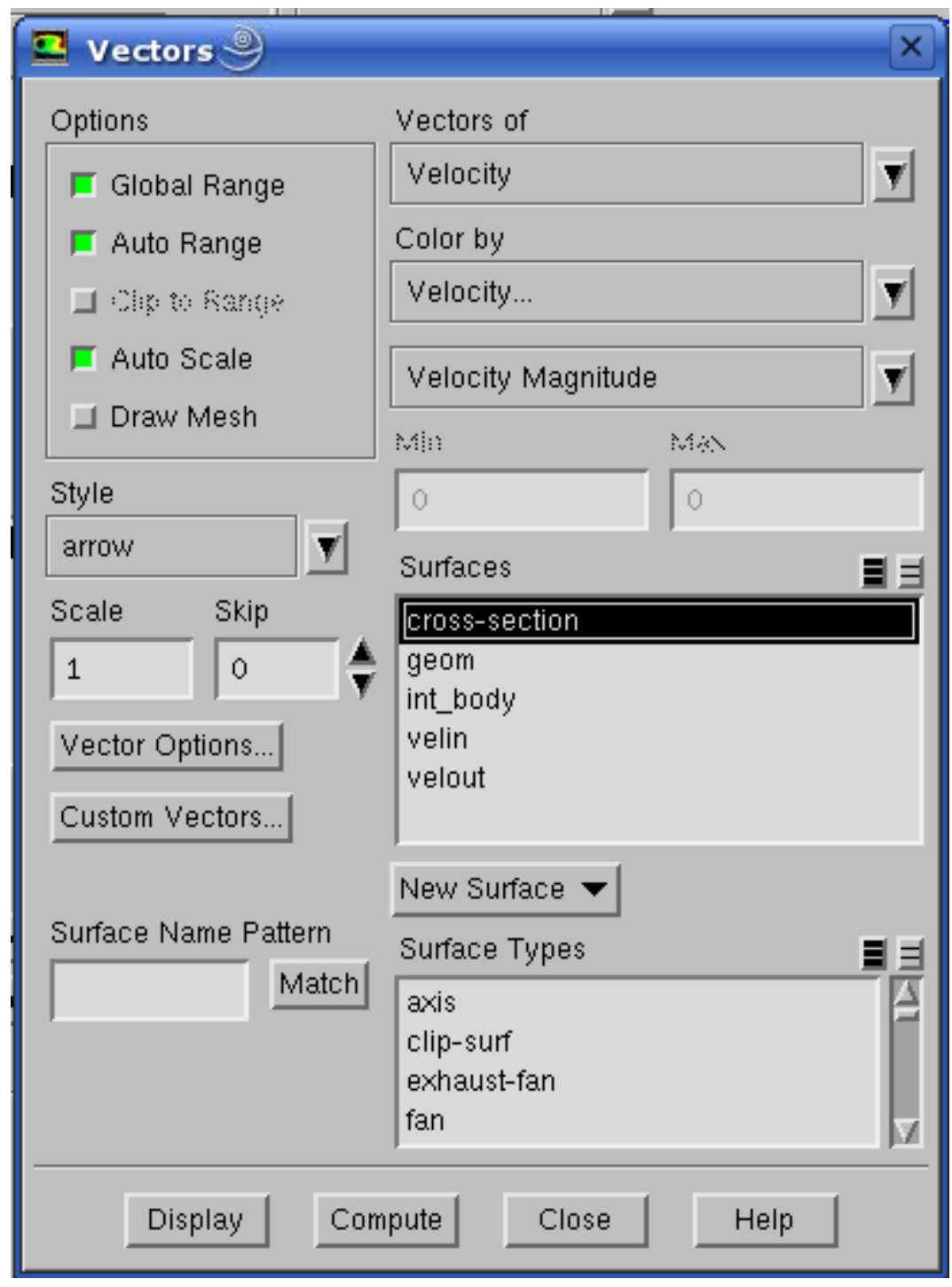

Figure 23: View Vectors Menu 


\section{RESULTS AND DISCUSSION}

All designs for testing were provided by Westwind Power. The ten curves

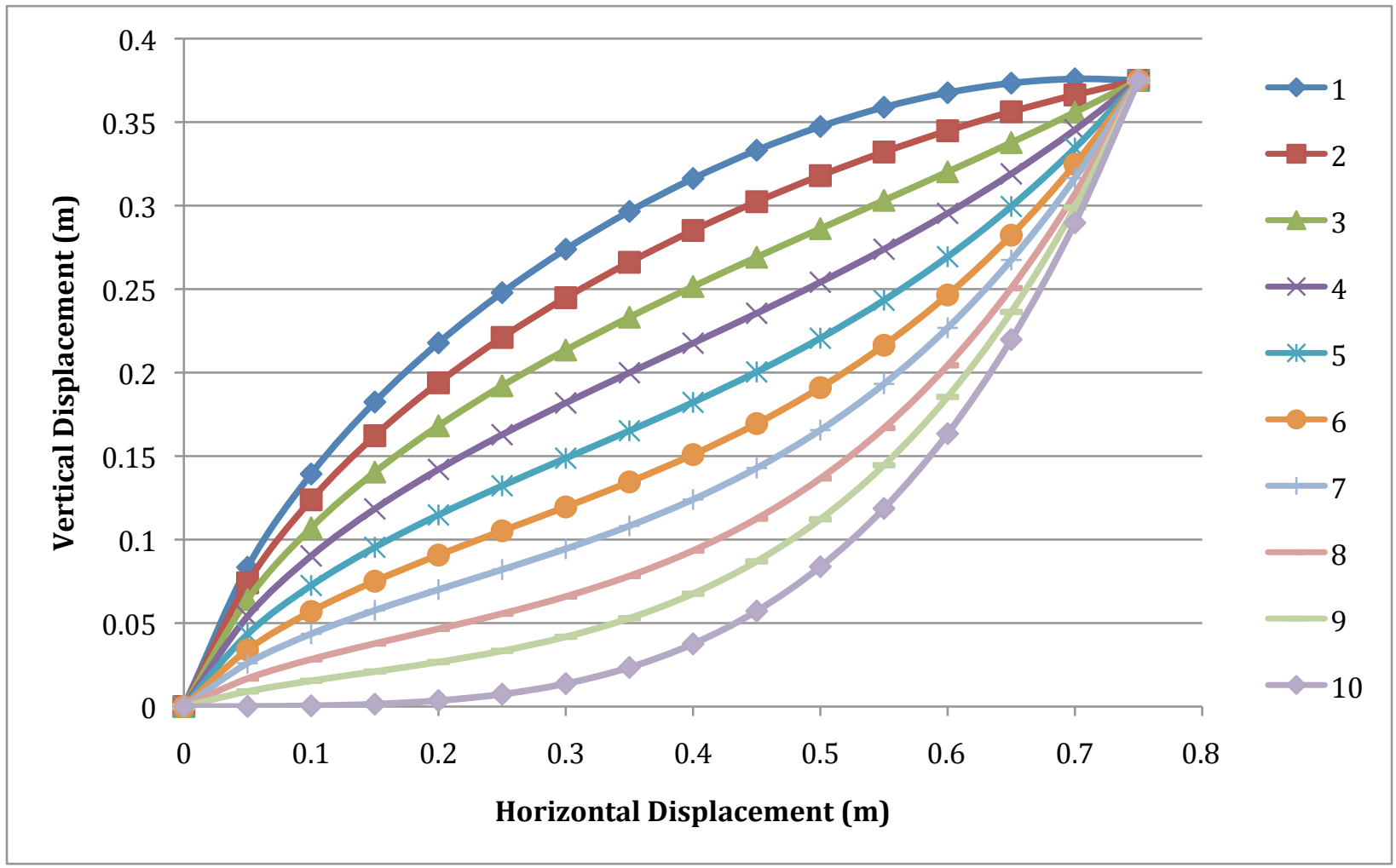

Figure 24: Visual representation of curves 1-10. Each curve was tested for the profile of the concentrator inlet.

representing the concentrator inlet shape that were tested are shown in Figure 24. These start as hyperbolic (\#1) and transition to parabolic (\#10). Curves \#4-6 have visible inflection points in them. Ideally, each of these curves would act as a funnel to drive air into the throat of the concentrator, where the turbine would be located. Then, by the continuity equation, the air speed would be faster, thus allowing for more energy 
generation. CFD simulations with $2 \mathrm{~m} / \mathrm{s}$ inlet wind speed resulted in the throat speeds shown in Tables 2-3. Figure 25 shows top throat speed under purely laminar conditions.

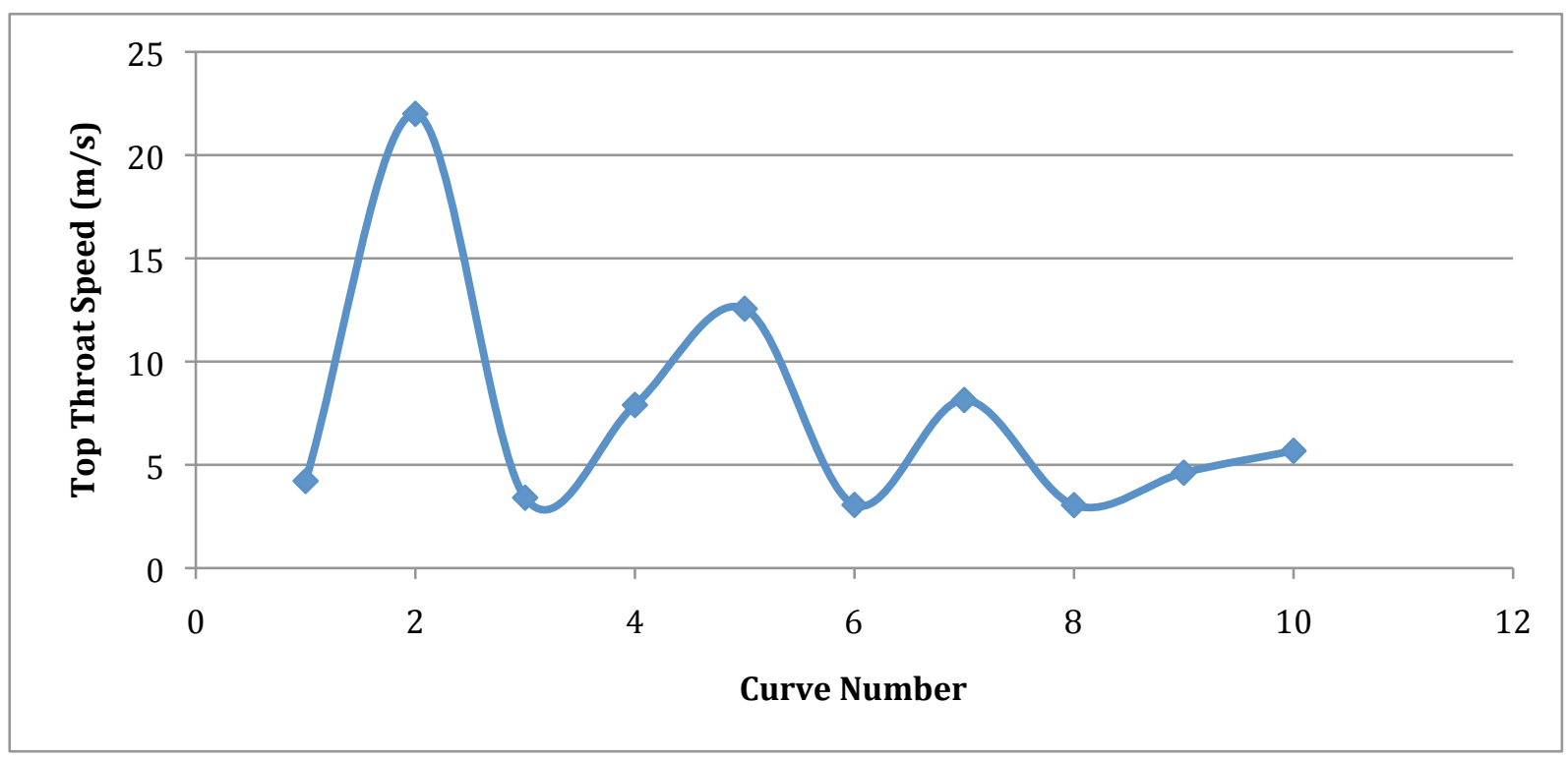

to inflection to parabola, since they exhibit four peaks, rather than three. This likely The

Figure 25: Top throat speed as a function of curve number when treated as laminar. Curve number refers to same description as in Figure 24.

data show an unexpected oscillating effect, with a sharp peak in maximum speed for curve \#2. These data oscillate too rapidly to be explained by the transition from hyperbola indicates the flow is not laminar. The viscosity of air is low enough that $2 \mathrm{~m} / \mathrm{s}$ wind speed creates turbulent conditions $(\mathrm{Re}=23000)$. Figure 26 shows the maximum throat speeds across all ten curves with an inlet wind speed of $2 \mathrm{~m} / \mathrm{s}$ when the simulations were performed using the turbulence model. These data show much less variability than do the laminar speeds. Also, the total increase in speed over the inlet conditions is significantly lower when considering turbulence ( $20 \mathrm{~m} / \mathrm{s}$ for laminar vs. $0.33 \mathrm{~m} / \mathrm{s}$ for turbulent). The results using the turbulence modeling correspond much more readily with actual conditions, and hence are more accurate. From Figure 26, it is evident that there is no 


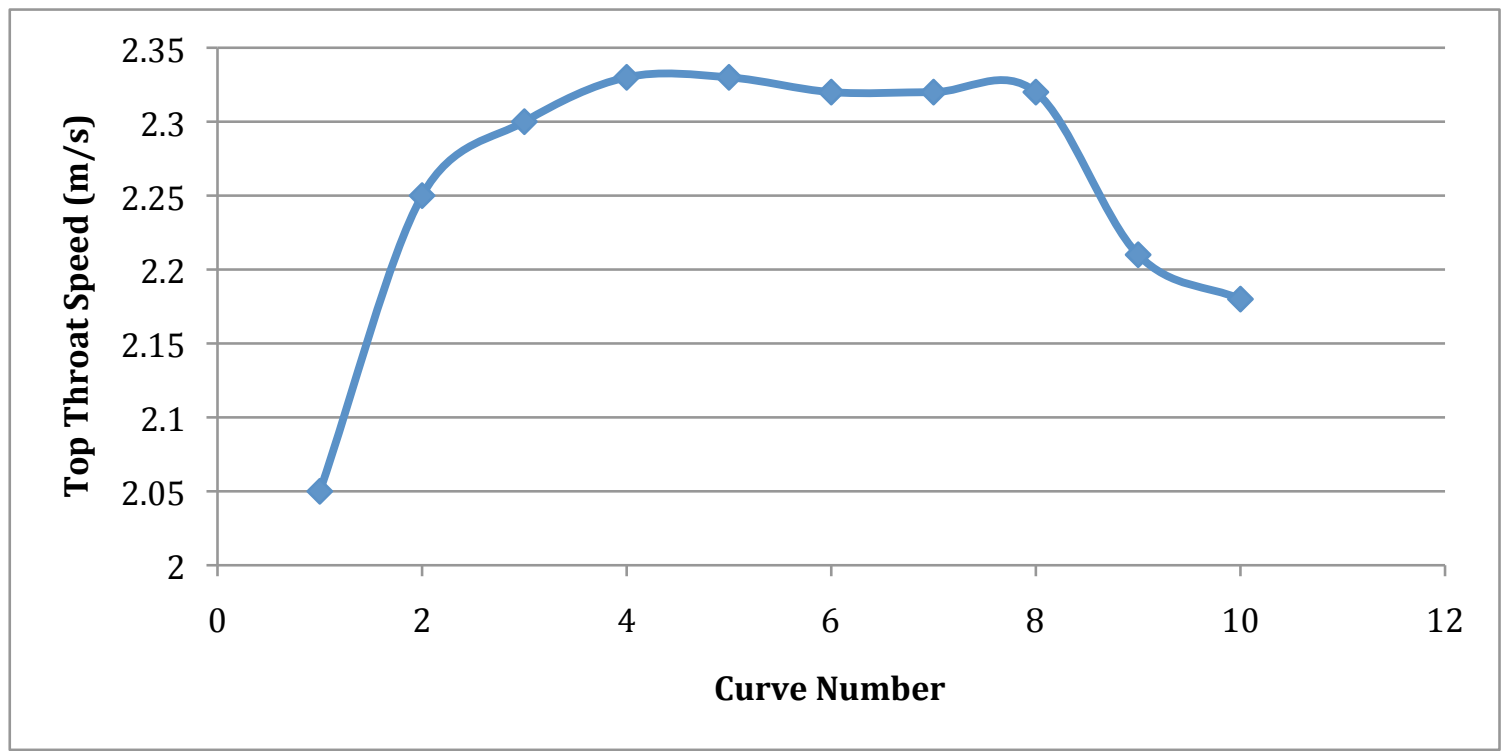

Figure 26: Top throat speed as a function of curve number when treated as turbulent. Curve number refers to the same description as in Figure 24.

strong difference in speed increase between curves \#3-8. This implies that a moderate design, avoiding either extreme of hyperbolic or parabolic, provides the most optimum curve. The higher rate at which the more extreme curves cause the air to change direction perhaps leads to less of the energy being transferred back to axial flow of the air. This can be seen in Figure 1, as curves \#1-2 are very steep at the beginning, curves \#9-10 are very steep at the end, while curves \#3-8 have a shallower slope the entire length. From these data, curve\#4 is the optimum design. Curve \#4 shows some hyperbolic traits, but the inflection point also leads to it resembling a straight funnel design. The top speed of 2.33 $\mathrm{m} / \mathrm{s}$ indicates a $17 \%$ increase in inlet wind speed.

Following the optimization of the inlet curve, the next goal was to test dimensions of the central cone. The cone and relief slits described below were tested jointly as part of a separate project, but results of both are presented here to completely describe the evolution of the overall design. Figure 27 shows an illustration of the full inlet system 
cross-section, including the cone. The cone acts to shroud the axis of the turbine, as well as to drive some wind to the tips of the turbine blades. At this point the wind speed can

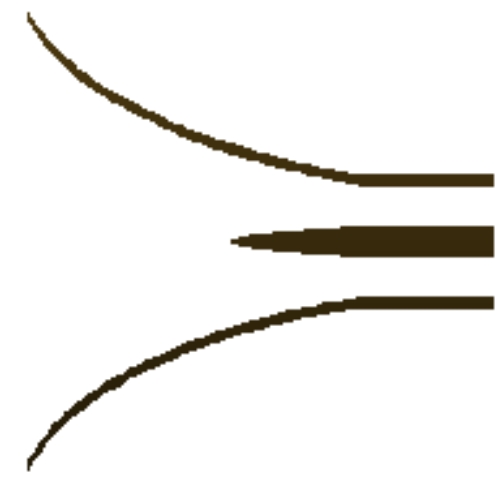

Figure 27: Visual representation of concentrator inlet profile including curve and cone.

exert more torque on the axis, and thus more easily transfer its energy to electricity. A basic parabola was chosen as the basic shape for the cone, since this is comparable to what is currently seen in industry. The inlet funnel shape used was the optimized curve \#4.

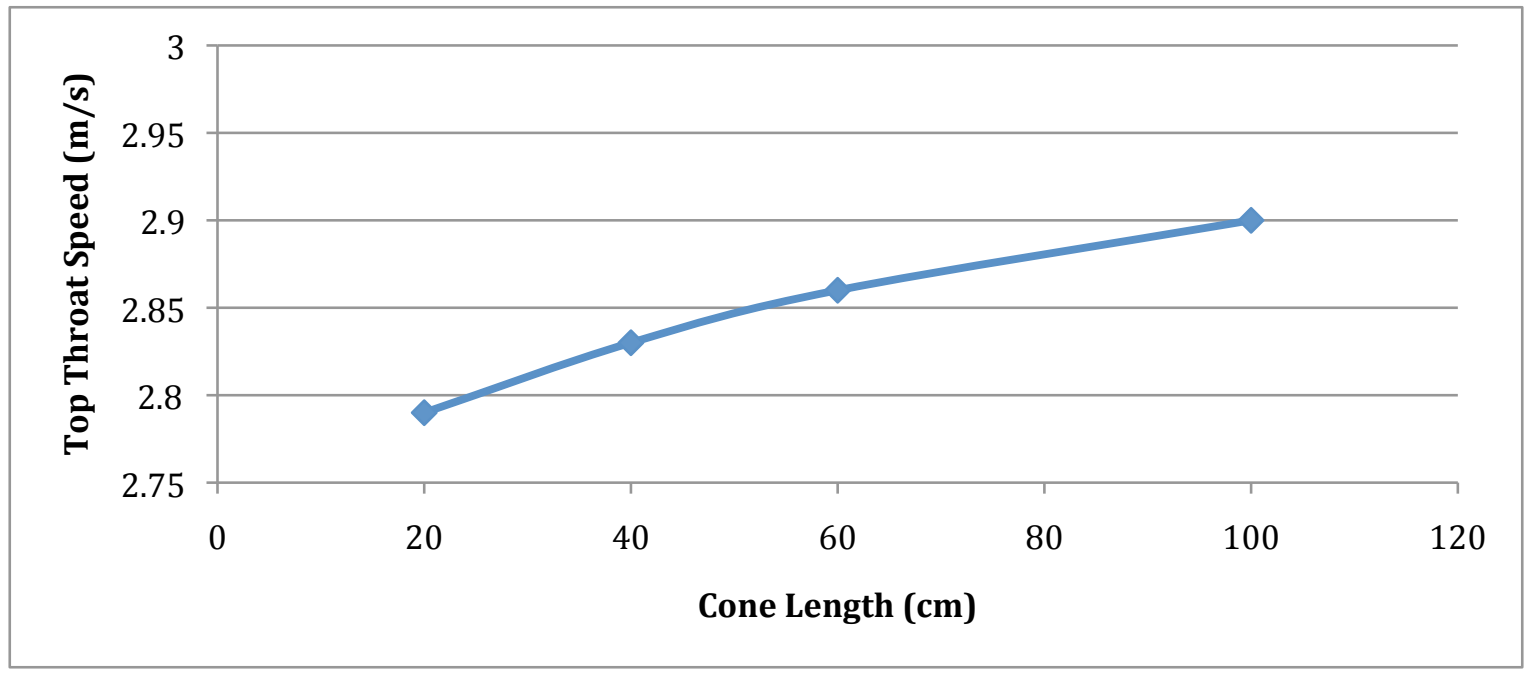

Figure 28: Relationship between cone length and top throat speed within concentrator.

Additionally, slight rounding was added to the tips of the inlet (so as to reduce turbulence discussed below and seen in Figure 31), since this will be the next device to optimize. 
Also, a basic hyperbolic exit section was attached past the throat section, following the cone. The two cone factors to optimize were the cone length and cone width. These were tested independently. Figure 28 shows the effect of cone length on top throat speed.

These show a strong trend towards a longer cone, as the maximum was obtained with the $100 \mathrm{~cm}$ cone. Longer cones could be tested, though anything much beyond 100 $\mathrm{cm}$ may be prohibitive due to size. Therefore, the $100 \mathrm{~cm}$ design was selected for further research. The optimized cone length provides a $4 \%$ increase to the throat speed as compared to the original length. Figure 29 shows why the longer cone is more effective.

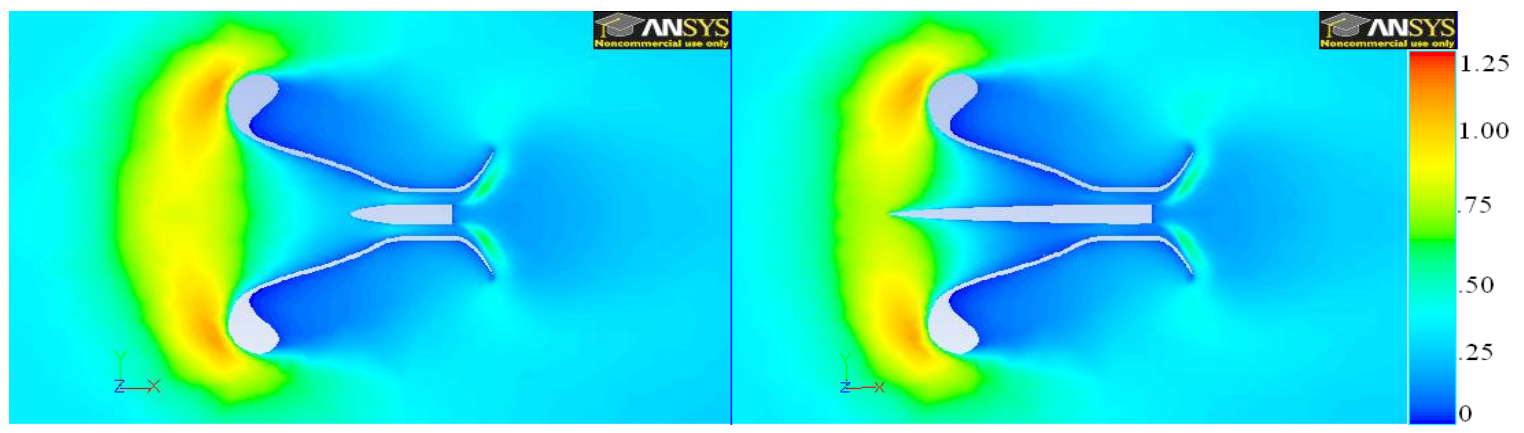

Figure 29: Comparison of turbulent energy $\left(\mathrm{m}^{2} / \mathrm{s}^{2}\right)$ between short cone (left) and long cone.

The magnitude of turbulence is shown at the inlet for both a shorter cone and the long, $100 \mathrm{~cm}$ cone. The band of high turbulence as the air reaches the device causes loss of maximum speed through the throat. In the image on the right, the long cone penetrates into this turbulent band. In the process, the thickness of the turbulence is reduced. Thus the overall frictional loss is reduced, leading to higher speed.

Also under consideration was the cone width. A wider cone would reduce the cross section of the throat annulus, thereby increasing speed as predicted by the continuity equation. Conversely, redirecting more air would create more friction, thus working 
against the desired acceleration. Figure 30 shows the results of several cone widths tested.

The same maximum speed was achieved at $2 \mathrm{~cm}$ and $8 \mathrm{~cm}$, which were the two narrowest

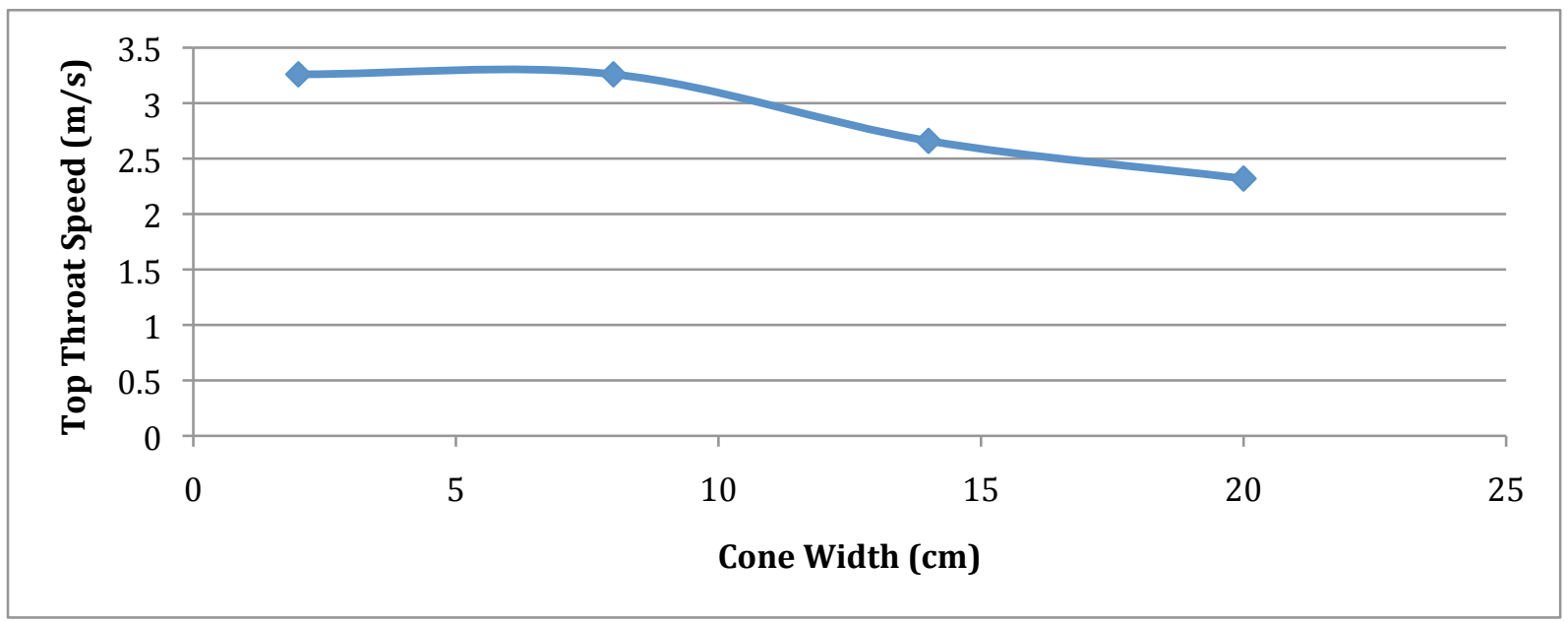

Figure 30: Relationship between cone width and top throat speed within concentrator.

cones tested. The new top speed of $3.26 \mathrm{~m} / \mathrm{s}$ indicates a $23 \%$ increase over the original cone width tested. As the wider cones tested produced inferior results, it is evident that the frictional losses in this case outweigh the gains caused by narrowing.

The next concern was to reduce turbulent friction at the inlet to the concentrator. The tip of the funnel is the very first part of the machine to contact the incoming wind, and so it is the major source of turbulence. In the original design, the funnel begins with a

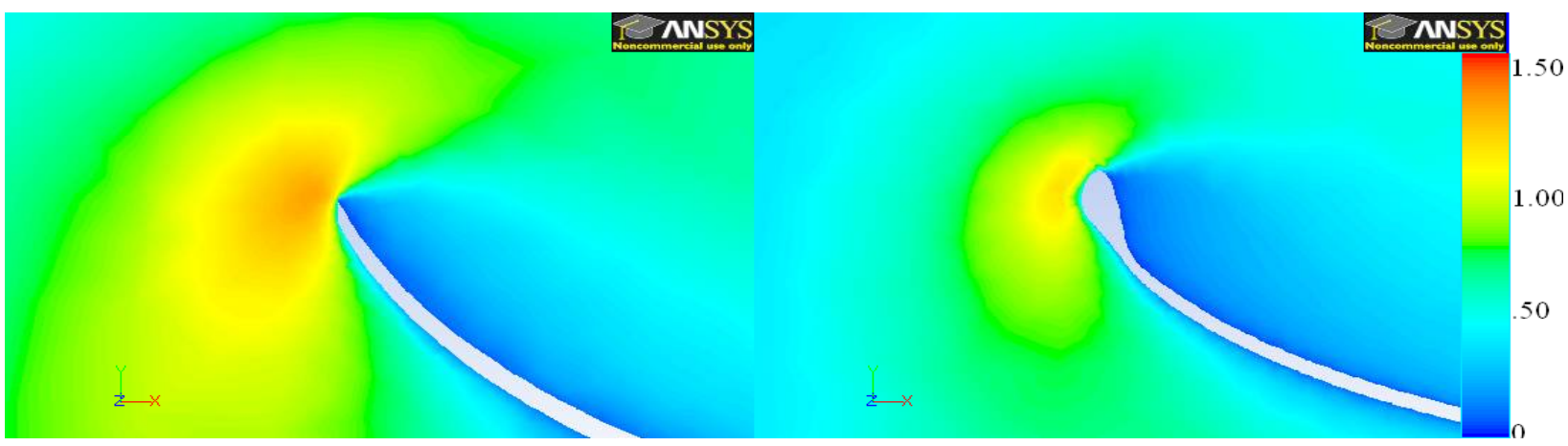

Figure 31: Comparison of turbulent energy $\left(\mathrm{m}^{2} / \mathrm{s}^{2}\right)$ between sharp tip (left) and rounded tip (right). 
sharp lip. This sharpness forces the air to redirect very quickly, thus generating the excessive turbulence. To overcome this, the tip of the inlet was rounded off. Figure 31 shows the effects on the turbulence with just a rudimentary rounding. The sharp point creates a much larger and higher intensity region of turbulence. Since the important criterion however for designing this device was to maximize throat speed, the next trials were compared quantitatively the effects of various degrees of rounding. Three models

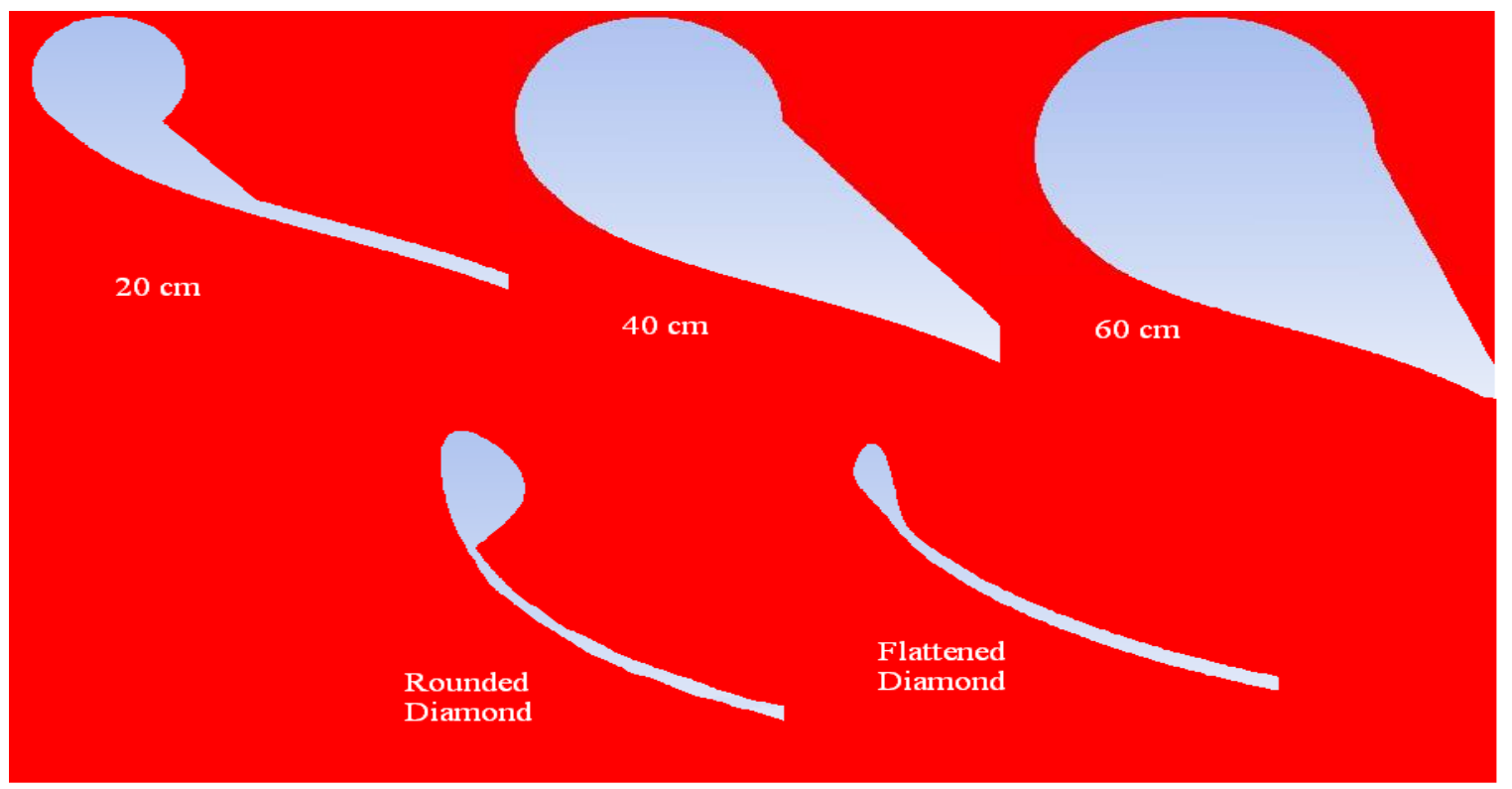

\section{Figure 32: Comparison of inlet tip shapes}

were tested using circles tangent to the inlet, with varying radii of curvature.

Additionally, a tight rounded diamond was tested, to essentially remove the sharpness without dramatically changing the cross section. Finally, a larger diamond flattened on

\section{Table II: Top throat speeds at various inlet tip curvatures}

$\begin{array}{ll}\text { Tip of Radius of Curvature }(\mathrm{cm}) & \text { Top Throat Speed }(\mathrm{m} / \mathrm{s}) \\ 20 & 3.24 \\ 40 & 3.28 \\ 60 & 3.36 \\ \text { Rounded Diamond } & 3.31 \\ \text { Flattened Diamond } & 3.17\end{array}$


the inlet end was tested. These are shown in Figure 32. Table II shows the results of these trials. In general, the larger circles allowed for faster throat speeds. However, the rounded diamond tip performed almost as well as the largest circle tested $(\sim 1 \%$ difference), and created a much more manageable profile to build, so this design was selected for further testing. This was the initial design used in previous trials (as seen in Figure 31), so there was no increase in maximum throat speed during this stage of testing. The next step was to test designs of the exit section. The exit section serves to redirect air away from the throat as quickly as possible. Without it, the air exiting the throat region would immediately rejoin the dead air in the shadow of the device. Thus the higher speed stream would meet a near-still stream, causing turbulence and backpressure. By creating an exit section that expands hyperbolically, the air can expand and slow down gradually, resulting in a smoother stream. Models with exits of lengths varying from 45 $\mathrm{cm}$ to $210 \mathrm{~cm}$ were tested, with the results shown in Figure 33 . The $150 \mathrm{~cm}$ length resulted in a maximum throat speed of $4.21 \mathrm{~m} / \mathrm{s}$. Beyond this length, the speeds began to drop

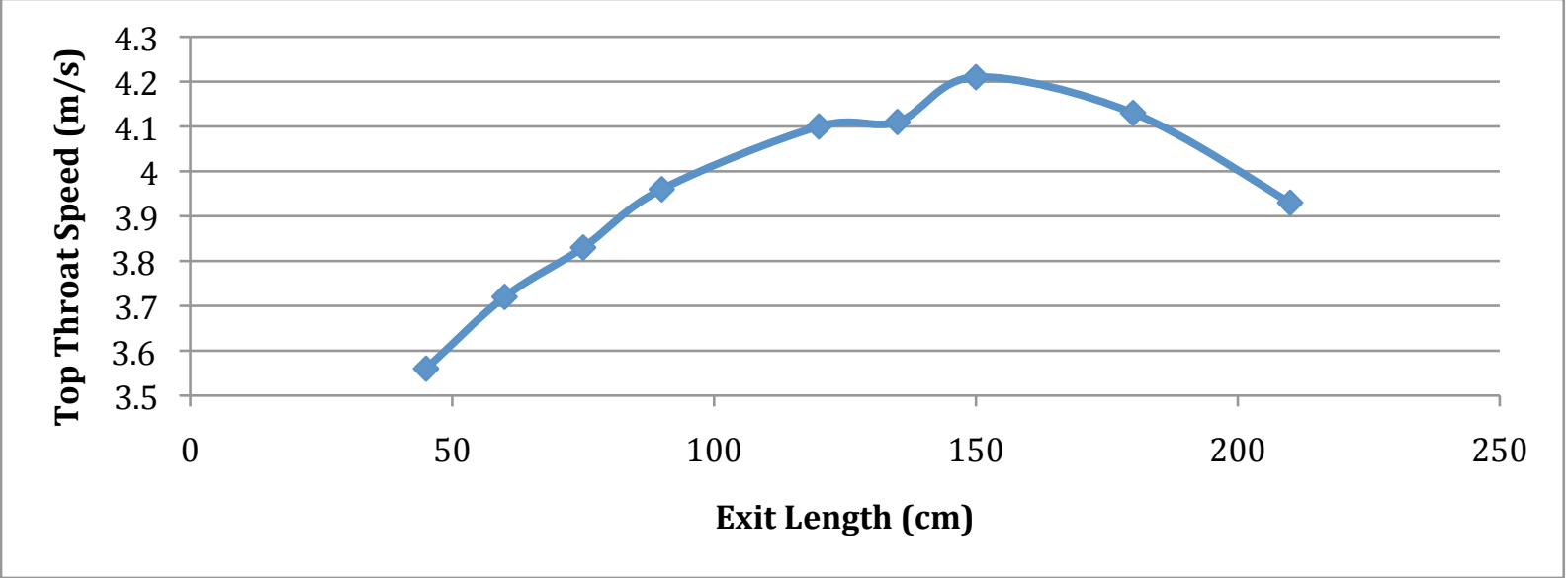

Figure 33: Relationship between exit length and top throat speed within concentrator. 
sharply. This is probably due to increased skin friction along the wall of the exit section. While expanding the outlet stream more gradually had a positive effect up to $150 \mathrm{~cm}$, frictional effects became significant beyond $150 \mathrm{~cm}$. Thus, $150 \mathrm{~cm}$ is the optimal length of the exit section. The maximum speed of $4.21 \mathrm{~m} / \mathrm{s}$ indicates an $18 \%$ increase in throat speed.

With the entrance, cone, and outlet optimized, dimensions of the model were set. However, when examining the pressure profile of the system, it was apparent that there was still room for improvement. Figure 34 shows this pressure profile. In all models tested to this point, there is evidence of backpressure within the concentrator, which

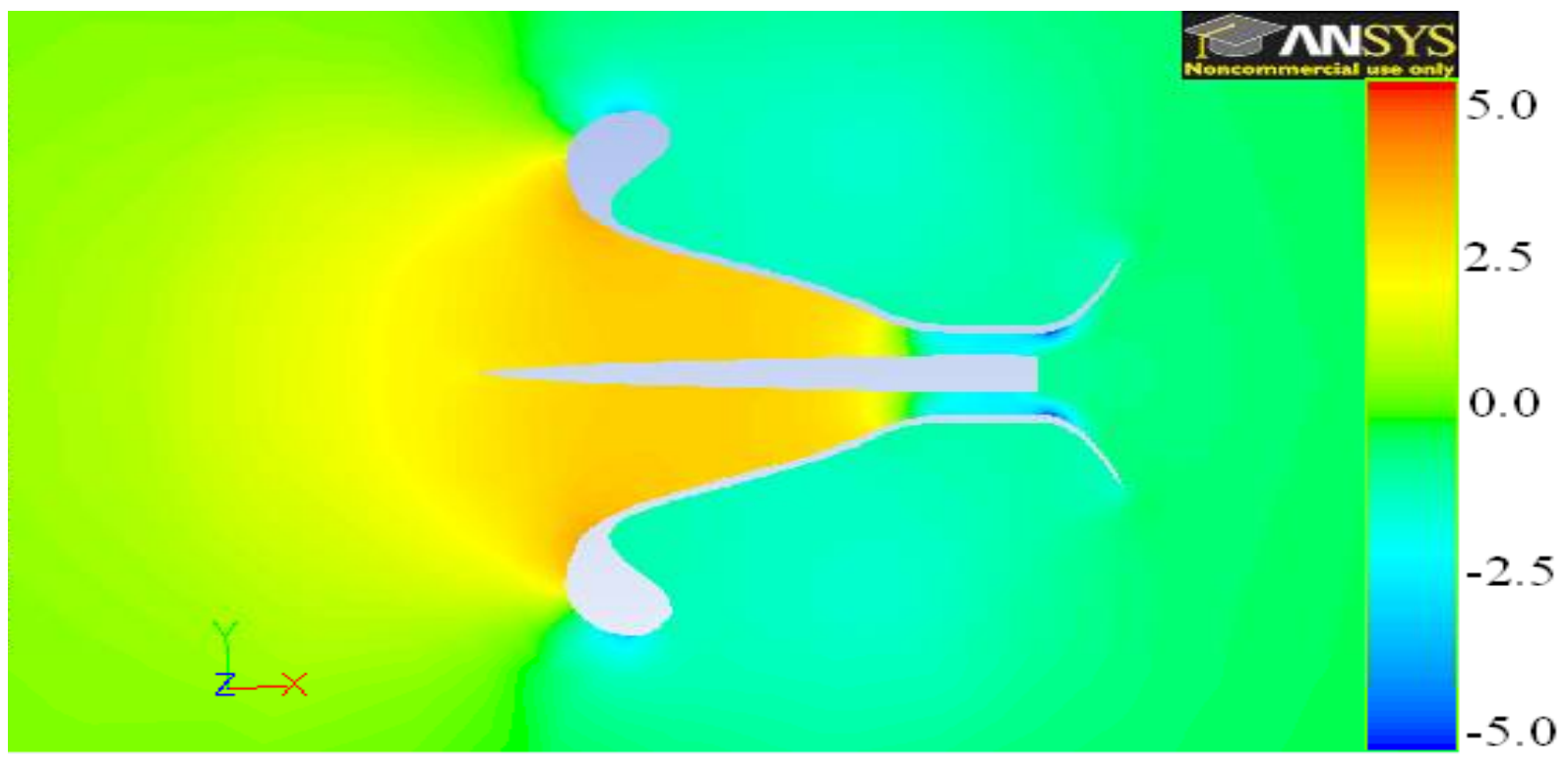

Figure 34: Profile of gauge pressure within concentrator. (Pa)

prevents air from speedily entering the device and passing through the throat. Pressure relief vents were then incorporated to remedy this. These vents, or slits, are located along the inside of the inlet curve and allow some air to pass out of the concentrator. The idea is that by allowing some air to escape, the pressure wall would be reduced and more air could easily pass into the throat of the device. Figure 35 shows the change to the pressure 
profile. The pressure increase within the concentrator is severely reduced ( $28 \%$ decrease) allowing for air to pass more freely into the throat. Additionally, without the pressure buildup, the turbulence in that region is significantly diminished (32\% reduction). Figure 36 shows the turbulent energy before and after the relief slits. Notice the turbulence is much more confined to the wall regions, and that air flowing down the middle of the concentrator is relatively un-impinged. Including these relief slits (M. Lucas, personal communication, April 2010) brought the maximum throat speed up to $4.26 \mathrm{~m} / \mathrm{s}$,

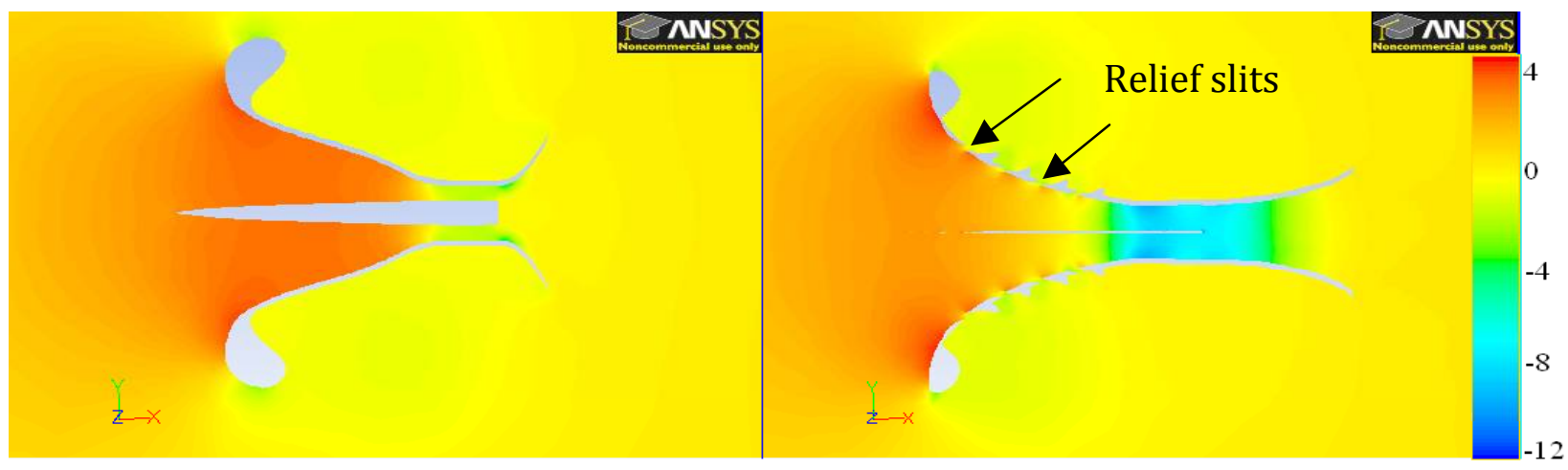

Figure 35: Comparison of gauge pressure within concentrator before (left) and after addition of relief slits. (Pa)

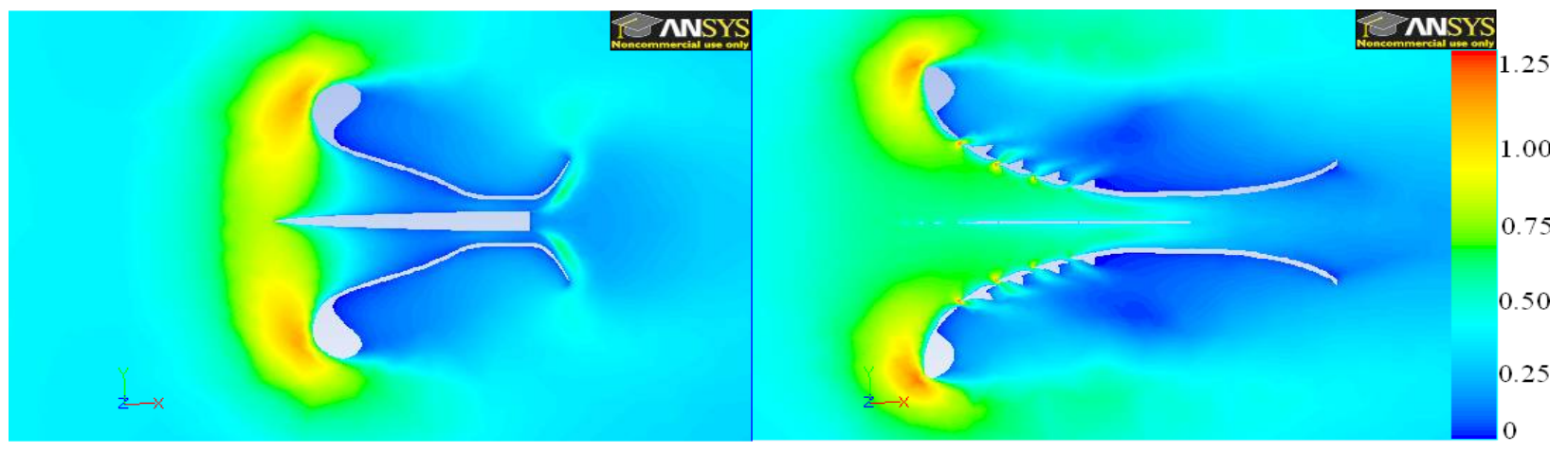

Figure 36: Comparison of turbulent energy before (left) and after addition of relief slits. $\left(\mathrm{m}^{2} / \mathrm{s}^{2}\right)$

a $1 \%$ increase. Though this is a small speed increase, the effects on the turbulence and pressure indicate there is still more room for optimization. While the slits will increase 
difficulty in manufacturing, this can be justified if further testing reveals a pressure and turbulence reduction, which can produce a large velocity gain.

The final step remaining was to ensure that the optimized individual components combine for an optimized whole. Exit length, cone length, and tip curvature were all retested within the context of the completed model. Table III shows the results from the second round of exit length testing. The original exit length

Table III: Throat speed at various exit lengths in the final optimization stage

$\begin{array}{cc}\text { Exit Length }(\mathrm{cm}) & \text { Throat Speed } \\ 30 & 3.39 \\ 60 & 4.55 \\ 67.5 & 4.55 \\ 75 & 4.50 \\ 90 & 4.20 \\ 120 & 3.40 \\ 150 & 4.20 \\ 180 & 3.45\end{array}$

proved to be too long, so it was shortened to $60 \mathrm{~cm}$. This shorter exit requirement is probably due to the increased friction from the air traveling at a higher speed across the walls of the outlet. Ergo, the shorter wall provided less friction, and allowed for a higher speed. Table IV shows the results from varying the cone length. The same trends were Table IV: Throat speed at various cone lengths in the final optimization stage

$\begin{array}{cc}\text { Cone Length }(\mathrm{cm}) & \text { Throat Speed }(\mathrm{m} / \mathrm{s}) \\ \text { No Cone } & 4.95 \\ 70 & 4.83 \\ 100 & 4.90 \\ 140 & 4.97\end{array}$

observed with regards to the cone as previously seen. Longer is best. Therefore, the cone was considered complete. The largest change in this final step occurred with the tip curvature. Figure 37 shows velocity vectors through and around the device. The airflow through the slits and along the outside of the throat allows much of the incoming wind to 
pass without substantially changing its direction. The very tip of the inlet and the rounded section causes the large still region surrounding the center of the device, much like a shadow. By removing this section entirely, the concentrator accelerates the air without changing the direction of most of the incoming wind. This resulted in a speed increase of $19 \%$ relative to the device with the inlet tips.

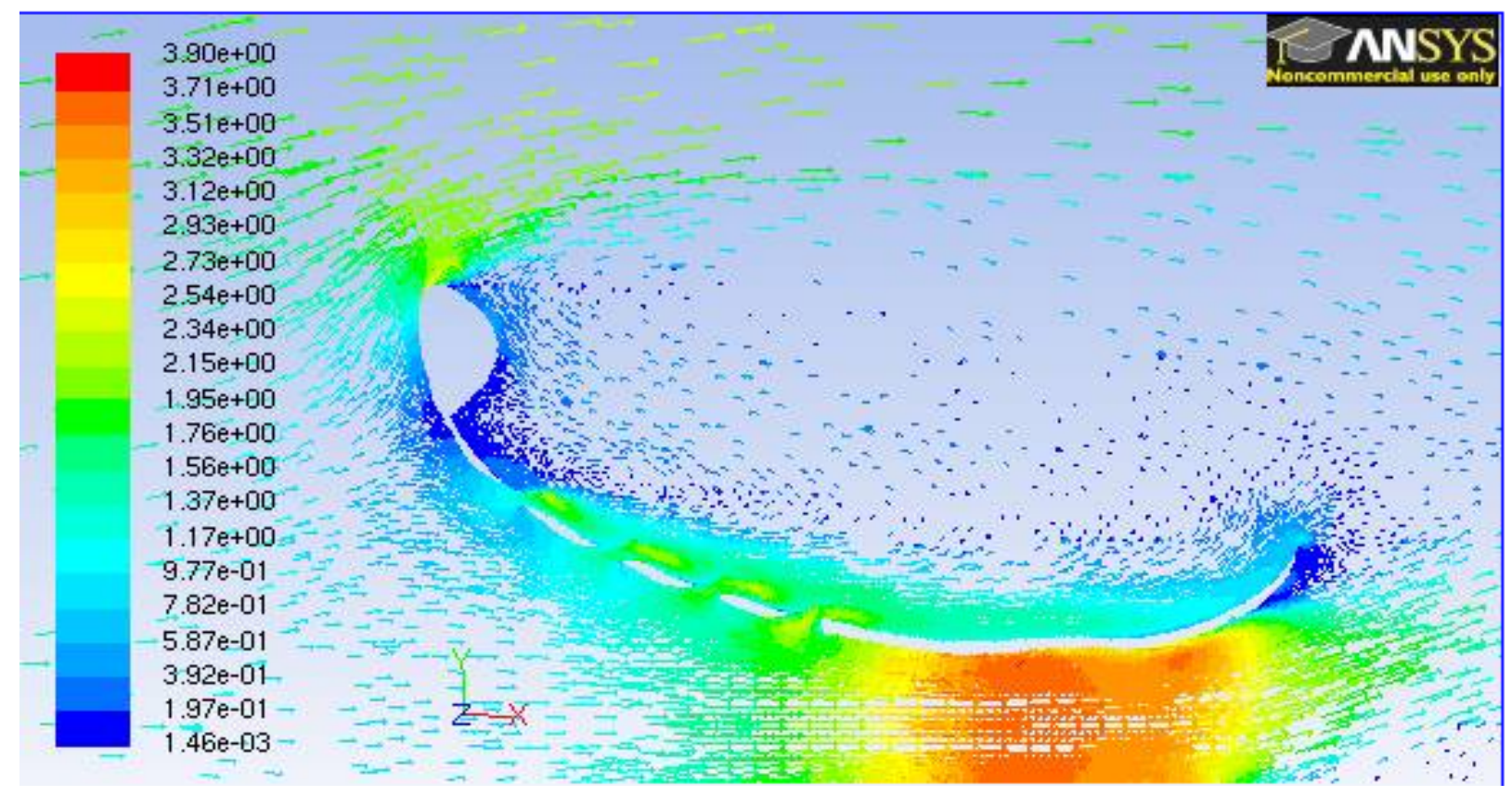

Figure 37: Velocity vectors of air through concentrator. $(\mathrm{m} / \mathrm{s})$

The final model increased the inlet air speed from $2 \mathrm{~m} / \mathrm{s}$ to $5.05 \mathrm{~m} / \mathrm{s}$, so that the speed of the wind hitting a turbine would be $2.53 \mathrm{X}$ higher than without the device. But since wind does not naturally blow at a constant speed, understanding how the device performs across a range of speeds is desirable. Figure 38 shows such analysis. When tested from 1-12 m/s at $1 \mathrm{~m} / \mathrm{s}$ increments, the speed multiplier appears to be constant. When a higher speed value of $50 \mathrm{~m} / \mathrm{s}$ was tested, it was apparent that the outlet to inlet wind speed ratio is a very slight exponential function. However, since the device is 
primarily designed for use with low wind speed conditions, a linear approximation ratio of $2.55: 1$ is sufficient in the $1-12 \mathrm{~m} / \mathrm{s}$ range.

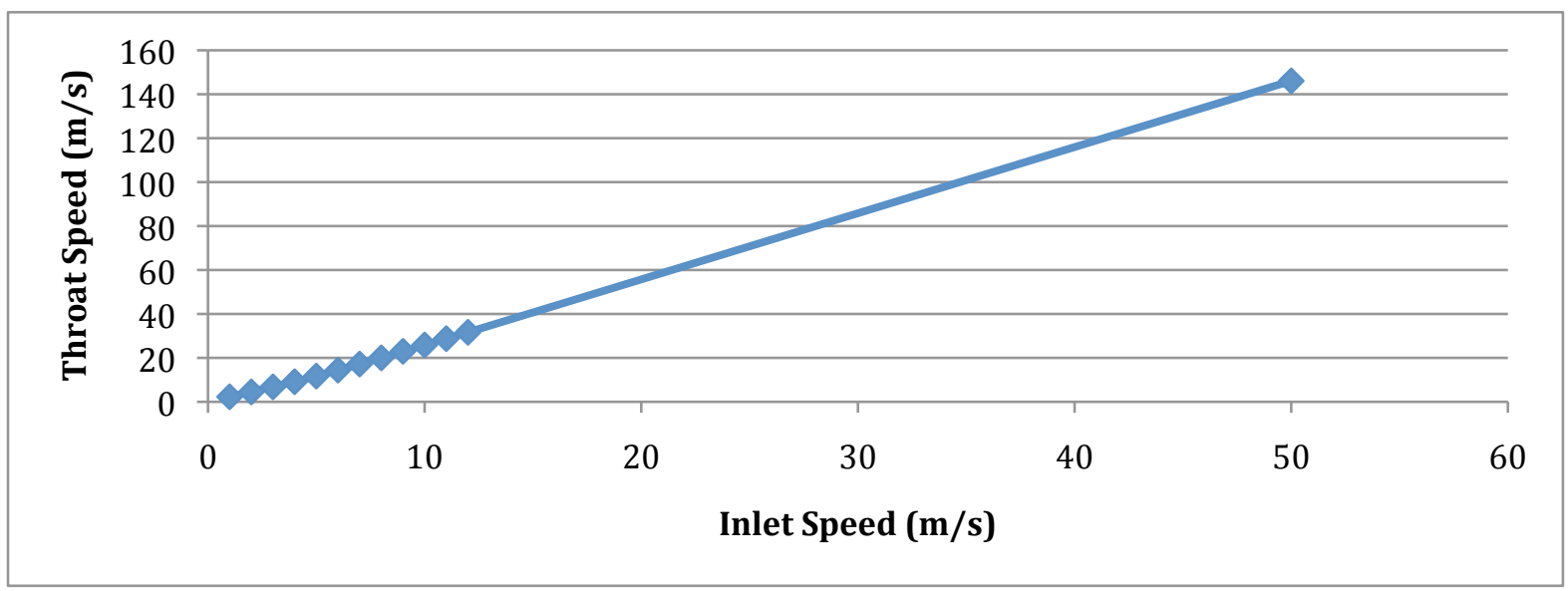

Figure 38: Throat speed as a function of inlet speed

A final analysis was conducted to determine the effect on performance of constructing a casing. The casing would provide no functional benefit for increasing wind speed, but would conceal and protect equipment such as a generator that would be attached to the device. The casing envisioned would be a simple cylindrical shell. The back end of the casing would need to be open so as to allow air flowing out of the slits to exit the device. Figure 39 shows the effect of the casing on the airflow velocities. Notice the appreciable air flow along the inner wall of the casing area from the slits. Provided the casing is far enough away from the device, it should not cause much detriment to performance. However, there was a 7\% reduction in speed through the throat. Upon closer analysis, this was found to come from the exit region. Figure 40 shows the velocity vectors near the outlet of the casing. The curvature of the concentrator causes an eddy to develop near the end. With the addition of the casing, this eddy is constricted to the confines of the cylinder, and thus impinges upon the flow out of the slits. Nevertheless, 
the benefit due to protecting from the elements may be worth this small performance reduction.

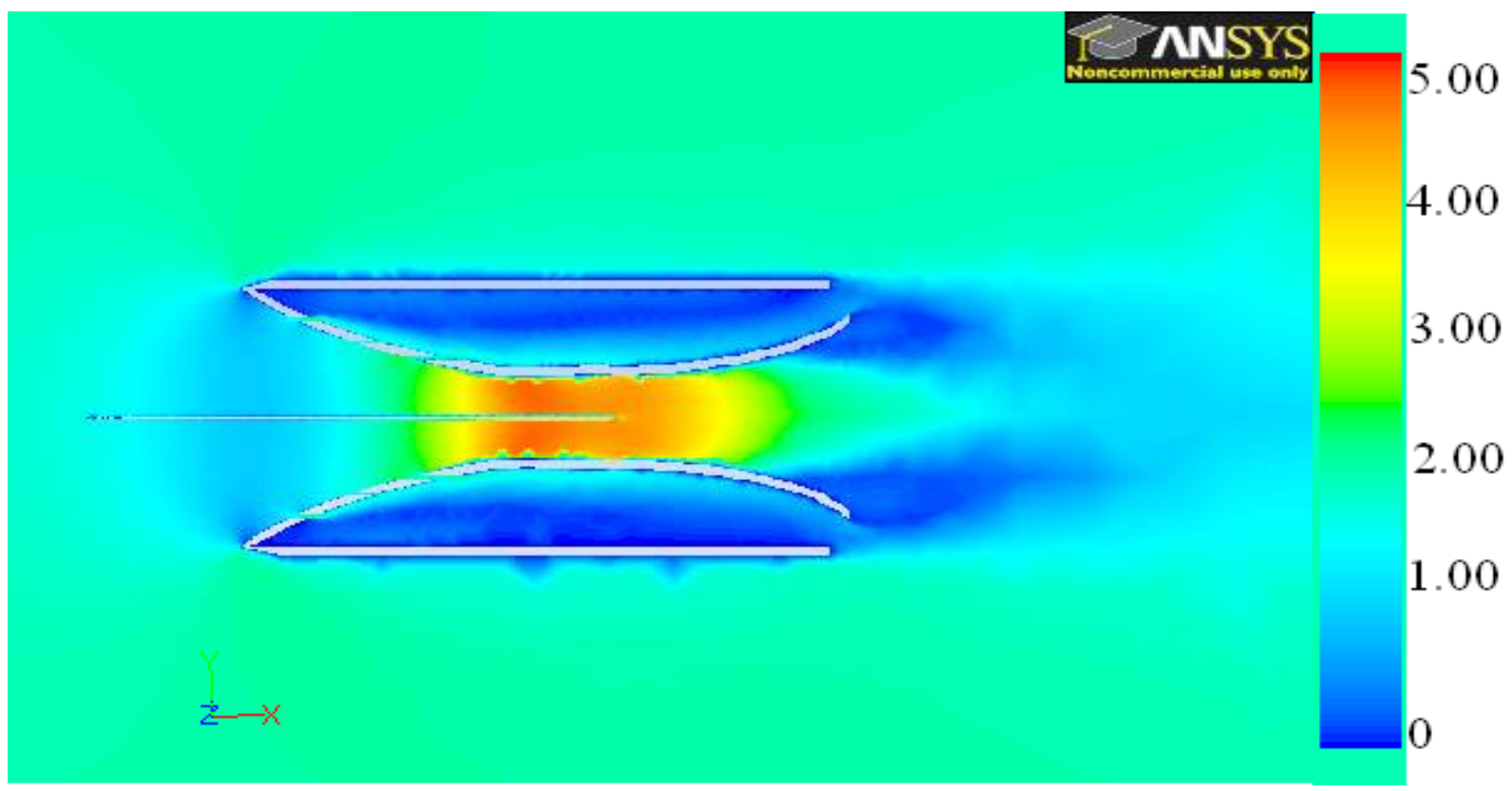

Figure 39: Velocity profile through concentrator with cylindrical casing. (m/s)

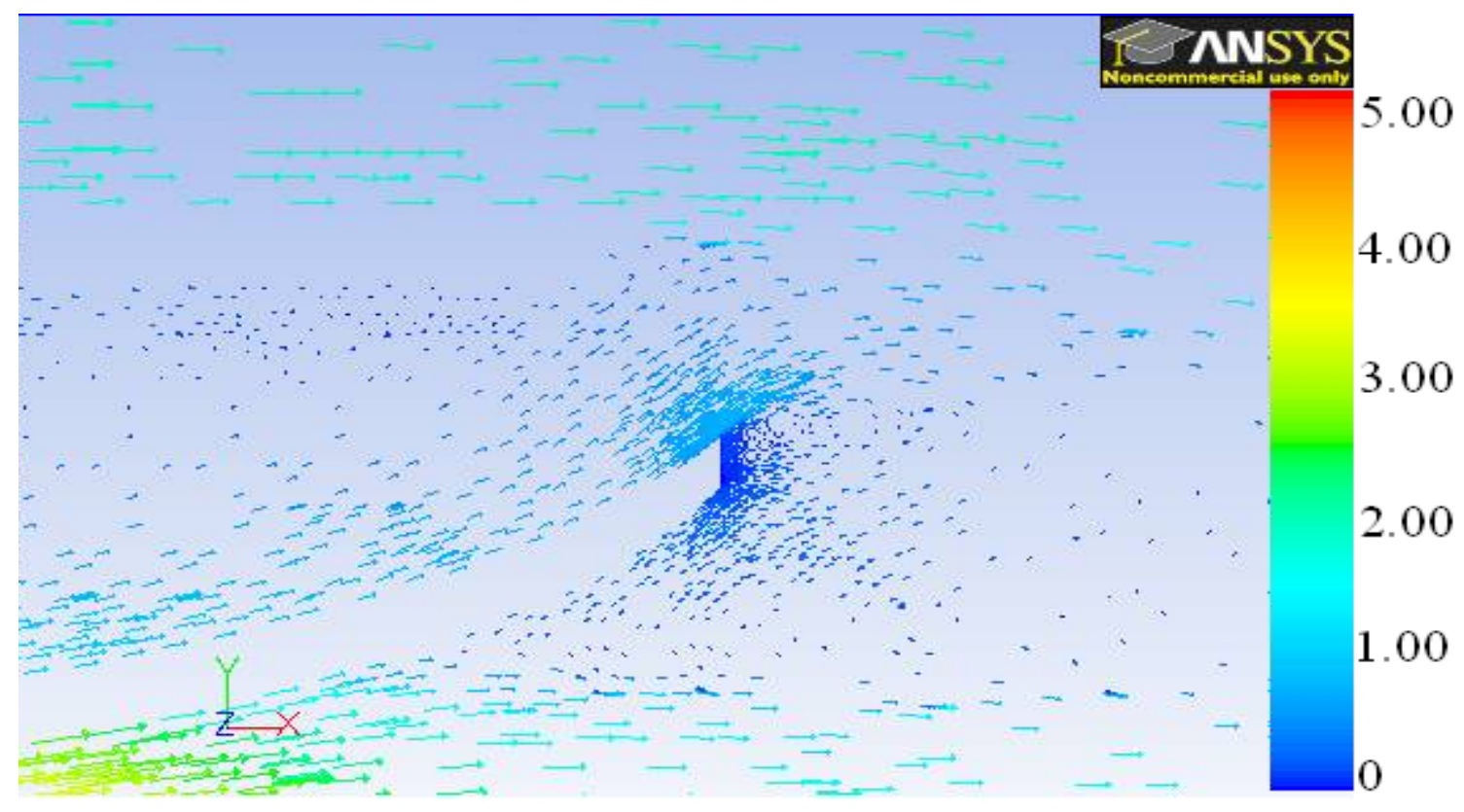

Figure 40: Velocity vectors of airflow through exit of cylindrical casing. (m/s) 


\section{CONCLUSIONS}

CFD trials were performed to analyze the wind acceleration effects of a wind concentrator for a small-scale wind turbine device. The final device increased wind speed through the throat section of the device from $2 \mathrm{~m} / \mathrm{s}$ ambient speed to $5.05 \mathrm{~m} / \mathrm{s}$, a $2.53 \mathrm{X}$ increase.

A funnel shape was the base starting point for design. A funnel shape that is slightly hyperbolic near the outlet, but cylindrical near the center resulted in the greatest speed increase when chosen within a range from hyperbolic to parabolic. This design resulted in a $17 \%$ increase in the observed throat speed. (A cone design intended as a flow straightener and pressure relief slits to allow for the relief of backpressure were added as part of a different project.)

During initial testing, it was observed that rounding of the tip of the inlet section led to an increase in maximum throat speed of $20 \%$. Before rounding, the tips generated significant turbulence across the entire inlet of the device. After rounding, the magnitude of this turbulence was reduced, as was the region of turbulence. The decrease in turbulence apparently decreased the friction of the inlet air, thus increasing the throat speed. 
A hyperbolic exit section allows air to expand and decelerate gradually, so as to reduce backpressure. The optimal length for this section was determined to be $60 \mathrm{~cm}$. Appending and optimizing this exit section allowed for an increase in throat speed of $18 \%$.

The most significant change made during the final step was the shortening of the inlet section. By this, the entire portion before the first slit was removed, including the rounded tip. The air velocity vectors around the device were less disturbed, and they more closely approximated the predicted vectors for a free stream of air not entering any type of device. This would reduce friction before and after the device, which in turn would positively affect the airflow through the device. Thus, the smaller cross section on the device captured more air through the throat. This final step led to a $19 \%$ increase in maximum throat speed.

With a final working design, a range of ambient wind speeds was tested. Across a range of $1-12 \mathrm{~m} / \mathrm{s}$ inlet speeds, the ratio of throat speed to inlet speed was seen to be a constant 2.55:1. Also, a trial to examine the effect of adding a cylindrical casing showed that such an addition would reduce the throat speed by $7 \%$. 
WORKS CITED

Calley, David G., and Harrison M. Knowler. Wind Turbine Controller. Calley Et Al, assignee. Patent 6703718. 9 Mar. 2004. Print.

Davis, Edward L. Ultimate Wind Turbine System Method and Apparatus. Davis, assignee. Patent 12/573,857. 5 Oct. 2009. Print.

Forsyth, Trudy, Carol Tombari, and Mike Nelson. "Lessons Learned from the U.S. Photovoltaic Industry and Implications for Development of Distributed Small Wind." Proc. of WINDPOWER 2006, Pittsburgh. Print.

Fosdick, George. Efficient Wind Turbine Design for Low Velocity Air Flow. Fosdick, assignee. Patent 4427343. 24 Jan. 1984. Print.

Fradella, Richard B. Broad-speed-range Generator. Fradella, assignee. Patent 7646178. 12 Jan. 2010. Print.

Gagnon, Francois. Wind Concentrator Turbine. Gagnon, assignee. Patent 61/245 461. 2010. Print.

Graham, John F. Wind Turbine System for Buildings. Graham, Sr., assignee. Patent 7315093. 1 Jan. 2008. Print.

Incropera, Frank P., David P. DeWitt, Theodore L. Bergman, and Adrienne S. Lavine. Fundamentals of Heat and Mass Transfer. Hoboken, NJ: John Wiley, 2007. Print. 
Launder, B. E., and Sharma, B. I. (1974), "Application of the Energy Dissipation Model of Turbulence to the Calculation of Flow Near a Spinning Disc", Letters in Heat and Mass Transfer, vol. 1, no. 2, pp. 131-138.

McCabe, Warren L., Julian C. Smith, and Peter Harriott. Unit Operations of Chemical Engineering. Boston: McGraw-Hill, 2005. Print.

Presz, Walter M., and Michael J. Werle. Wind Turbine With Mixers and Ejectors. Presz, Jr. Et Al, assignee. Patent 12/437,615. 8 May 2009. Print.

Tocher, Angus J. Habitat Friendly, Pressure Conversion, Wind Energy Extraction. Tocher, assignee. Patent 6887031. 3 May 2005. Print.

United States. Department of Energy. National Renewable Energy Laboratory. Calculating Wind Integration Costs: Separating Wind Energy Value from Integration Cost Impacts. By Michael Milligan and Brendan Kirby. 2009. Print. Zhang, Jialin, Zhenggui Zhou, and Yansheng Lei. "Design and Research of Highperformance Low-speed Wind Turbine Blades." WNWEC 2009 - 2009 World NonGrid-Connected Wind Power and Energy Conference. Nanjing. Piscataway, NJ: IEEE Computer Society, 2009. 161-65. Print. 


\section{APPENDIX}

\section{Final Design}

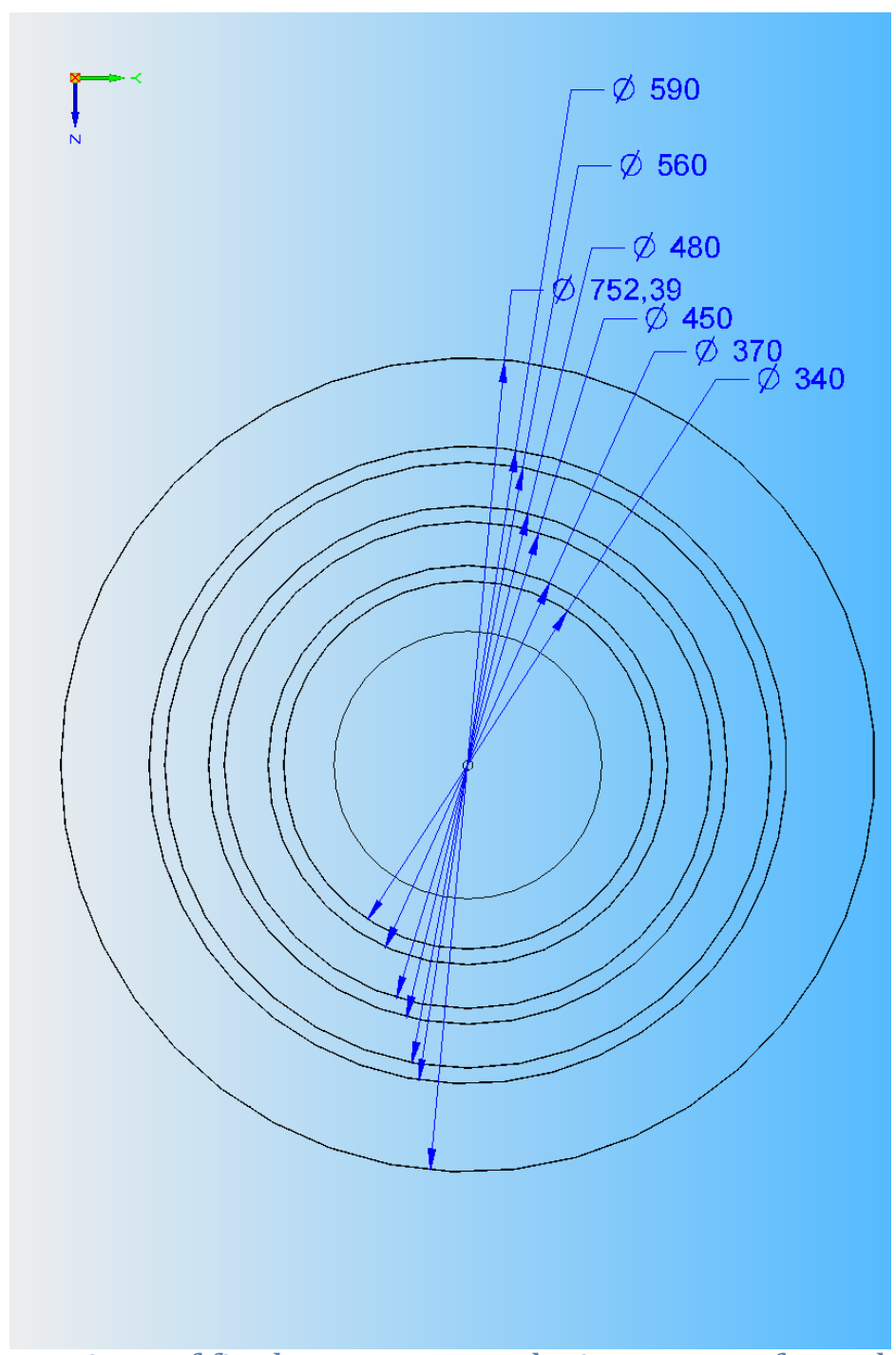

Figure 41: Dimensions of final concentrator design as seen from the front. (mm) 


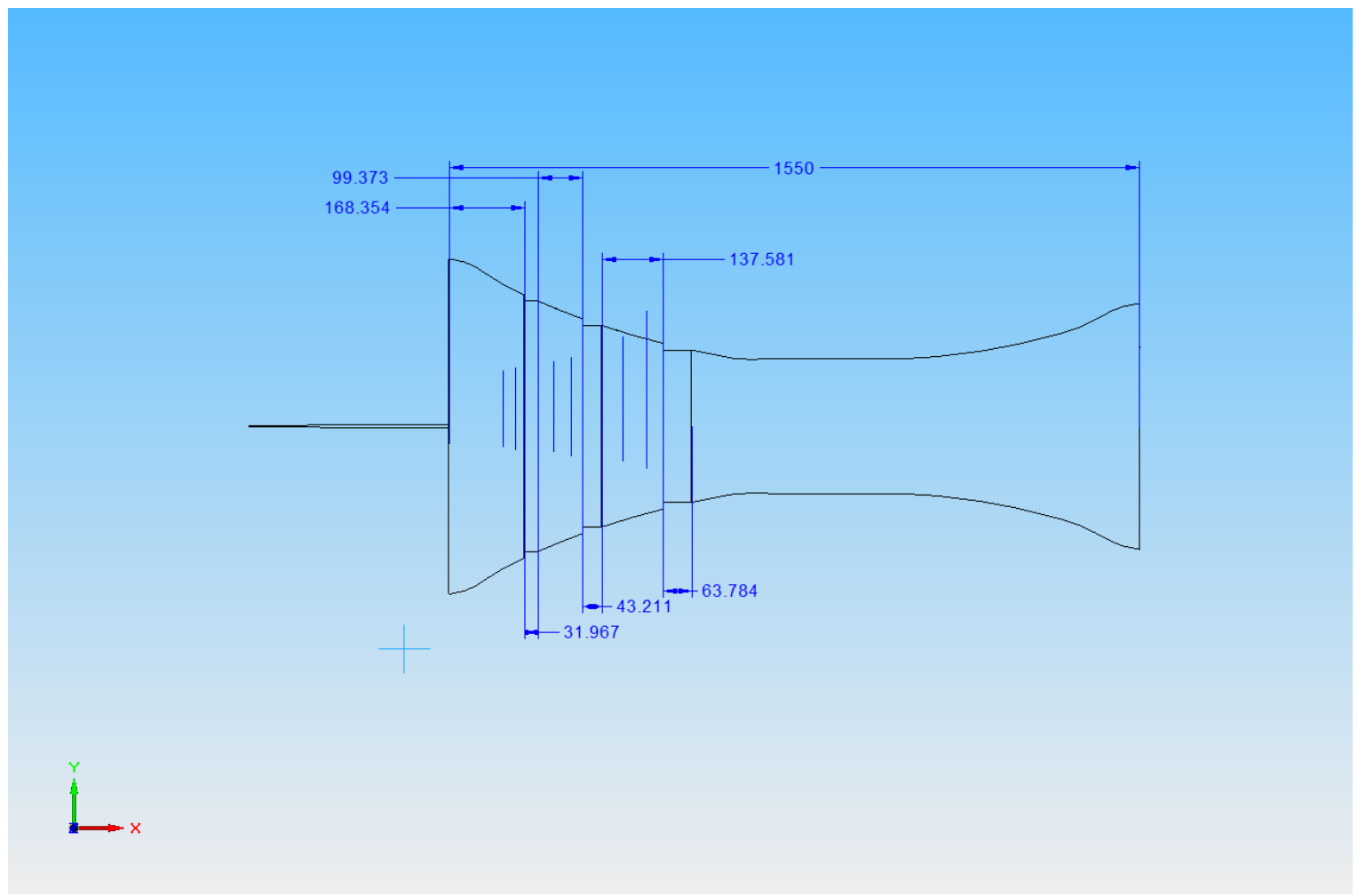

Figure 42: Dimensions of final concentrator design as seen from the side. (mm) 
VITA

David Russ was born in Winston-Salem, NC in 1987. In 2006 he graduated from Christian Academy of Louisville. He attended the University of Louisville, from where he received a B.S. in Chemical Engineering in 2010. He currently is a Master of Engineering student at Louisville, expecting to complete this degree in 2011. Following this, he will continue at Louisville as a University Fellow, seeking his Ph.D. degree in Chemical Engineering. His research focuses on computational fluid dynamics as applied to various aspects of renewable energies. 